
(1)

\title{
Perineuronal nets set the strength of thalamic recruitment of interneurons in the adult visual cortex
}

Giulia Faini ${ }^{1}$, Andrea Aguirre ${ }^{1}$, Silvia Landi ${ }^{2}$, Tommaso Pizzorusso ${ }^{3,4}$, Gian Michele Ratto ${ }^{2}$, Charlotte Deleuze ${ }^{1 *}$, Alberto Bacci ${ }^{1 *}$

${ }^{1}$ ICM - Institut du Cerveau et de la Moelle épinière - CNRS UMR 7225 - Inserm U1127 Sorbonne Université, Paris, France.

${ }^{2}$ National Enterprise for nanoScience and nanoTechnology, Institute Nanoscience-CNR and Scuola Normale Superiore, Pisa, Italy

${ }^{3} \mathrm{CNR}$, Istituto di Neuroscienze, Pisa, Italy

${ }^{4}$ Dip. NEUROFARBA, Università di Firenze, Firenze Italy

*Correspondence to: $\underline{\text { alberto.bacci@icm-institute.org or charlotte.deleuze@icm-institute.org }}$ 


\section{Summary}

In the neocortex, the closure of critical periods (CPs) of plasticity is paralleled by the accumulation of perineuronal nets (PNNs) around parvalbumin (PV)-positive inhibitory interneurons. Accordingly, PNN degradation in adult mammals re-opens cortical plasticity. However, how PNNs tune cortical function and plasticity is unknown. We found that PNNs modulated the gain of visual responses in the adult mouse visual cortex in vivo. Removal of PNNs in adult V1 strongly increased thalamic neurotransmission selectively on layer 4 PV cells. This produced a differential gating of feed-forward inhibition on principal neurons and other PV cells, with no alterations of unitary inhibitory synaptic transmission and neuronal excitability. These effects depended on visual input, as they were strongly attenuated by monocular deprivation in PNN-depleted adult mice. Thus, PNNs control visual processing and plasticity by selectively setting the strength of thalamic recruitment of PV cells. We conclude that PNN accumulation during circuit maturation likely prevents excessive thalamic excitation of PV cells at the expense of cortical plasticity.

\section{Introduction}

During postnatal maturation, sensory processing goes through a critical period $(\mathrm{CP})$, a developmental interval, in which neural circuits are shaped by sensory experience. After this time window, plasticity declines significantly, and learning becomes more difficult (Hensch, 2005;Espinosa and Stryker, 2012). In the visual cortex, the closure of the CP is paralleled by the structural maturation of the extracellular matrix, and, in particular, of perineuronal nets (PNNs). These are composed by a conglomeration of chondroitin sulphate proteoglycans, extracellular matrix and cell-adhesion molecules that, in the neocortex, accumulates selectively around fast-spiking, PV basket cells (Pizzorusso et al., 2002;Berardi et al., 
2004;Bernard and Prochiantz, 2016). Importantly, chemical breakdown of PNNs reactivates ocular dominance plasticity in the adult visual cortex (Pizzorusso et al., 2002), promotes juvenile forms of extinction of fear memories in the amygdala (Gogolla et al., 2009) and functional recovery after brain injury (Bradbury et al., 2002; Gherardini et al., 2015). plasticity, restricting the extent to which a neural circuit can change during late postnatal development (Berardi et al., 2004).

PV cells represent a major subtype of cortical GABAergic interneurons, specialized in providing fast and reliable perisomatic inhibition to principal neurons (PNs), thereby controlling their output spiking properties and driving network oscillations in the $\beta-\gamma-$ frequency range (Freund and Katona, 2007;Isaacson and Scanziani, 2011;Buzsaki and Wang, 2012; Tremblay et al., 2016). In addition to controlling cortical circuit activity (Hensch, 2005;Buzsaki and Wang, 2012), PV cells shape sensory plasticity (Fagiolini et al., 2004;Hensch, 2005;Donato et al., 2013;Toyoizumi et al., 2013;Kuhlman et al., 2013;Gogolla et al., 2014;Lensjo et al., 2017;Takesian et al., 2018). In particular, the strength of inhibition from PV cells was proposed to define the temporal window of the $\mathrm{CP}$ of cortical plasticity: increasing GABAergic neurotransmission accelerates the onset of the $\mathrm{CP}$, whereas a reduction of inhibition delays the onset of plasticity (Fagiolini et al., 2004;Hensch, 2005;Hensch and Fagiolini, 2005). Despite the mechanisms underlying the CP have been extensively studied (Hensch, 2005;Hubener and Bonhoeffer, 2014), very little is known about how PNN accumulation around PV cells changes the cellular and synaptic properties of these interneurons, thus affecting cortical circuits and limiting plasticity. In this context, it is crucial to pinpoint the functional mechanisms linking PNN accumulation around PV cells to its modulation of activity-dependent plasticity. Indeed, accumulating evidence indicates that dysfunctions of cortical circuits involving PV cells as well as PNN maturation are implicated 
in several psychiatric diseases including autism and schizophrenia (Marin, 2012;Sorg et al., 2016).

Here, we describe how PNN removal in adult mice altered the gain of visual processing and the power of $\gamma$-oscillations in vivo; we reveal the underlying synaptic circuitry and its sensitivity to sensory plasticity. In particular, we found that PNNs set the strength of thalamic inputs to PV cells selectively, leaving neuronal excitability and unitary synaptic GABAergic transmission from these interneurons intact. This resulted in a strong and differential modulation of feed-forward inhibition onto PNs and other PV cells. Importantly, plasticity induced by short monocular deprivation (MD) strongly attenuated these effects, indicating that PNN-mediated modulation of thalamic input onto PV cells depends on visual activity. plasticity in the adult visual cortex.

\section{Results}

PNN removal in adult mice increases the contrast adaptation gain and the power of $\gamma$ oscillations.

To test the effects of in vivo PNN removal on adult cortical circuit function, we stereotaxically injected the primary visual cortex (V1) of adult mice (>P70) with the bacterial enzyme chondroitinase $\mathrm{ABC}(\mathrm{ChABC}), 2-3$ days prior to electrophysiological experiments (see Methods). This is a standard procedure to effectively and locally disrupt PNNs, revealed by the absence of Wisteria floribunda agglutinin staining (WFA, Figure 1A,B) (Pizzorusso et al., 2002;Lensjo et al., 2017). Importantly, this approach was shown to re-open adult cortical plasticity (Pizzorusso et al., 2002; de et al., 2013). We first measured gain adaptation of contrast perception, which is a fundamental computation performed by the primary visual 
bioRxiv preprint doi: https://doi.org/10.1101/374587; this version posted July 23, 2018. The copyright holder for this preprint (which was not certified by peer review) is the author/funder. All rights reserved. No reuse allowed without permission.

cortex (Carandini and Ferster, 1997;Anderson et al., 2000). We recorded visually-evoked

extracellular potentials (VEPs) in V1 of adult mice in response to an alternating checkerboard

of varying contrast presented to the contralateral eye (Figure 1C,D). We found an

enhancement of adaptation in ChABC-injected animals, measured as a significant decrease of

the slope of the transfer function (Figure 1E). Moreover, the spectral power of the local field

potential during both resting state and visual activity was increased by ChABC treatment in

the high $\gamma$-frequency band (40-80Hz; Figure 1F-I) consistent with a previous report (Lensjo et

al., 2017). Importantly, PV cells are known to strongly modulate the gain of contrast

sensitivity (Atallah et al., 2012), and improve network synchrony during $\gamma$-oscillations

(Cardin et al., 2009;Sohal et al., 2009;Isaacson and Scanziani, 2011;Buzsaki and Wang,
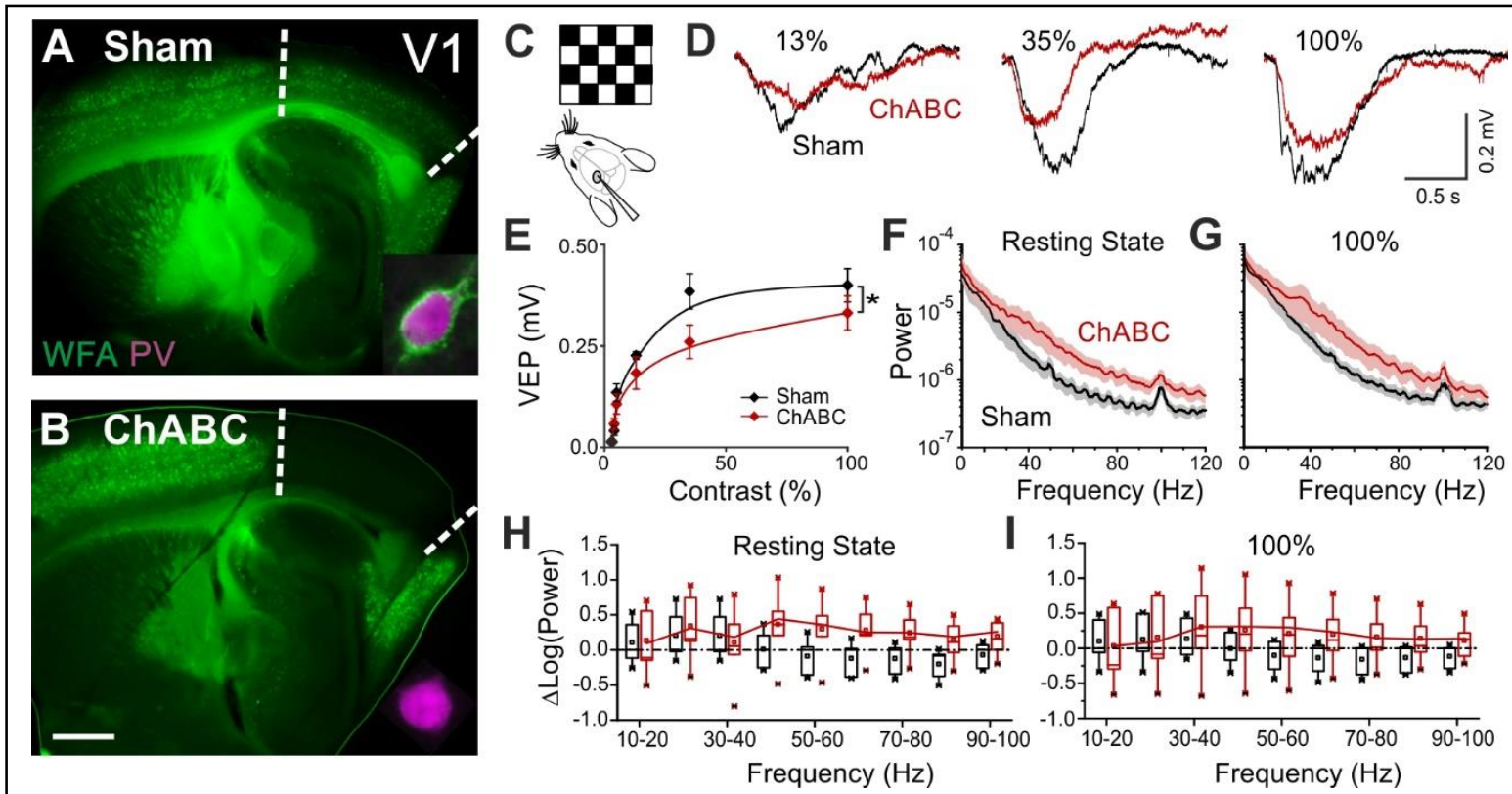

$F_{10^{-4}}$ Resting State

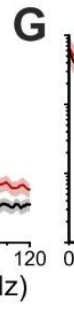

$100 \%$

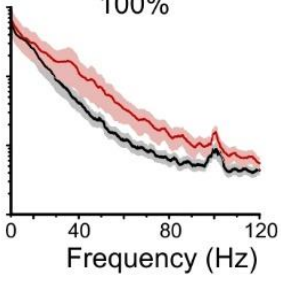

Frequency $(\mathrm{Hz})$

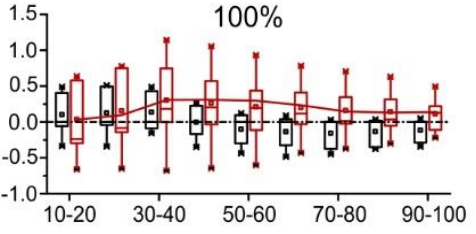

Figure 1. PNN removal in adult mice increases the contrast adaptation gain and the power of $\gamma$ oscillation.

A, Representative micrograph of a sagittal brain slice (thickness: $350 \mu \mathrm{m}$ ) from a control animal, whose visual cortex was injected with PBS (Sham). PNNs are stained with WFA (green) and are present throughout the cortex, including V1 (delimited by dotted lines). The inset shows a magnified micrograph of a cell stained with an anti-PV antibody (magenta), enwrapped by PNNs. B, Same as in (A), but from a slice obtained from a ChABC-treated mouse. PNN disruption in V1 is indicated by the absence of WFA staining. The inset illustrates a PV cell devoid of PNNs. Scale bar: $500 \mu \mathrm{m}$; inset: $20 \mu \mathrm{m}$ C, Experimental setup. Visual evoked potentials (VEPs) are recorded by a glass microelectrode in the primary visual cortex in the hemisphere injected with either Sham or ChABC. D, Typical recordings in Sham (black) and after PNN degradation (red). Each recording is the average of 20 sweeps. E, Transfer function in Sham (black) and after ChABC treatment (red). The two curves exhibit different slopes (*: p<0.05; ANOVA). F-G, Power spectra recorded in resting state $(\mathrm{F})$ and during visual stimulations $(\mathrm{G})$ in control (black) and ChABCtreated (red) animals. Note the differences in the two animal groups. H-I, Box plots representation of LFP power bins in resting state $(\mathrm{H}$; Two-Way ANOVA, post-hoc Holm Sidak, $\mathrm{p}<0.001)$ and during visual activity (I; Two-Way ANOVA, post-hoc Holm Sidak, p<0.005). 
2012). Therefore, our results suggest that the enzymatic disruption of PNNs results in stronger inhibitory interneuron activity during visual stimulation.

\section{Enhanced glutamatergic recruitment of PV cells by thalamocortical fibers in the} absence of PNNs is modulated by sensory deprivation.

Increased perisomatic inhibitory activity in vivo could be explained by one or a combination of the following causes: $i$ ) increased intrinsic excitability and/or spiking activity of inhibitory interneurons, $\mathrm{ii}$ ) alterations of the excitatory and/or inhibitory drive onto specific elements of the cortical networks favoring the recruitment of local GABAergic interneurons. We tested all these possibilities in L4 of V1, which is a prominent target of the visual thalamus and shows a stronger PNN enrichment around PV cells, as compared to other cortical layers (Figure S1A,B). Moreover, changes in the strength of thalamocortical connections were proposed to underlie visual cortical plasticity (Coleman et al., 2010;Jaepel et al., 2017). We recorded from PV cells and PNs in acute brain slices from adult (>P70) mice, which underwent PNN digestion in vivo, in the presence and absence of adult cortical plasticity, induced by short (2-3 days) monocular deprivation (MD; Methods and Figure S1C). Interestingly, action potential waveform, firing dynamics and passive membrane properties of both PV cells and PNs were unaffected by PNN digestion, in the presence and absence of MD (Figures S2-3; Tables S1-2). These results are in contrast with previous studies showing altered firing after acute PNN disruption in vitro (Dityatev et al., 2007;Balmer, 2016), or when the PNN protein brevican was knocked out (Favuzzi et al., 2017).

We then analyzed glutamatergic synaptic transmission on PV cells and PNs. Enzymatic disruption of PNNs significantly increased amplitude and frequency of spontaneous excitatory postsynaptic currents (sEPSCs) onto PV cells (Figure 2A,B; Table S3). 
Conversely, glutamatergic transmission onto PNs was unaffected by $\mathrm{ChABC}$ treatment (Figure S4A-D; Table S3). Increased neurotransmission onto PV cells following PNN removal was due to quantal synaptic transmission, and not increased slice excitability as revealed by increased miniature (m)EPSC frequency in the presence of $1 \mu \mathrm{M}$ tetrodotoxin (TTX; Figure 2C,D; Table S3). Plasticity induced by MD (Pizzorusso et al., 2002;Berardi et al., 2004; de et al., 2013) significantly counteracted the strong increase of sEPSC amplitude and mEPSC frequency on PV cells in PNN-depleted mice (Figure 2E-H; Table S3; for ChABC-mediated effects on sEPSC amplitude and mEPSC frequency: $P<0.01$ in control vs. $P>0.05$ in MD), although sEPSC frequency remained potentiated. These results indicate that the increased synaptic recruitment of PV cells, induced by PNN degradation, is sensitive to visual input.

We then investigated if a specific glutamatergic pathway was involved. First, we studied intracortical circuitry but, surprisingly, we found a very low yield of connected intracortical PN-PV cell pairs in L4 of adult mice $(5 \%, \mathrm{n}=104)$, as opposed to young animals $(40 \%, \mathrm{n}=$ 20; Figure S5), likely because of re-routing of PN axons to L2/3 in adult mice. Therefore, we focused our attention on the thalamocortical pathway, which carries sensory information. Using adeno-associated viruses (AAVs), we expressed the light-sensitive opsin channelrhodospin 2 (ChR2) in the dorsolateral geniculate visual thalamic nucleus (dLGN) of adult mice (Figure 2I; Figure S6, see Methods). After 10-12 days, we injected either sham solution or ChABC in V1 of the same mice (Figure 2j; Figure S6A), and, in some cases, MD was performed at the time of $\mathrm{ChABC} /$ sham injection (Figure S6a). In the absence of PNNs, PV cells exhibited larger light-evoked monosynaptic thalamocortical responses (in the presence of TTX and the $\mathrm{K}^{+}$channel blocker 4-aminopyridine, 4-AP; see Methods) than in control mice (Figure 2K, Table S4). We analyzed threshold responses to reduce the risk of misinterpreting our results due to variable expression of ChR2 in different mice. Threshold 
bioRxiv preprint doi: https://doi.org/10.1101/374587; this version posted July 23, 2018. The copyright holder for this preprint (which was not certified by peer review) is the author/funder. All rights reserved. No reuse allowed without permission.

responses were obtained by setting the power of light stimuli yielding alternating synaptic

failures and responses (see Methods). Of note, light stimulation parameters used to evoke

threshold responses were overall similar across different animal groups in all conditions

(Table S4; $P>0.05$ ). Importantly, plasticity induced by MD significantly attenuated the

potentiated recruitment of PV cells by thalamic afferents in the absence of PNNs (Figure 2L;

Table S4; size effect Glass' delta: 2.11 vs. 1.75; control vs. MD, respectively, see Methods).

Similarly to spontaneous glutamatergic neurotransmission, PNN digestion did not affect

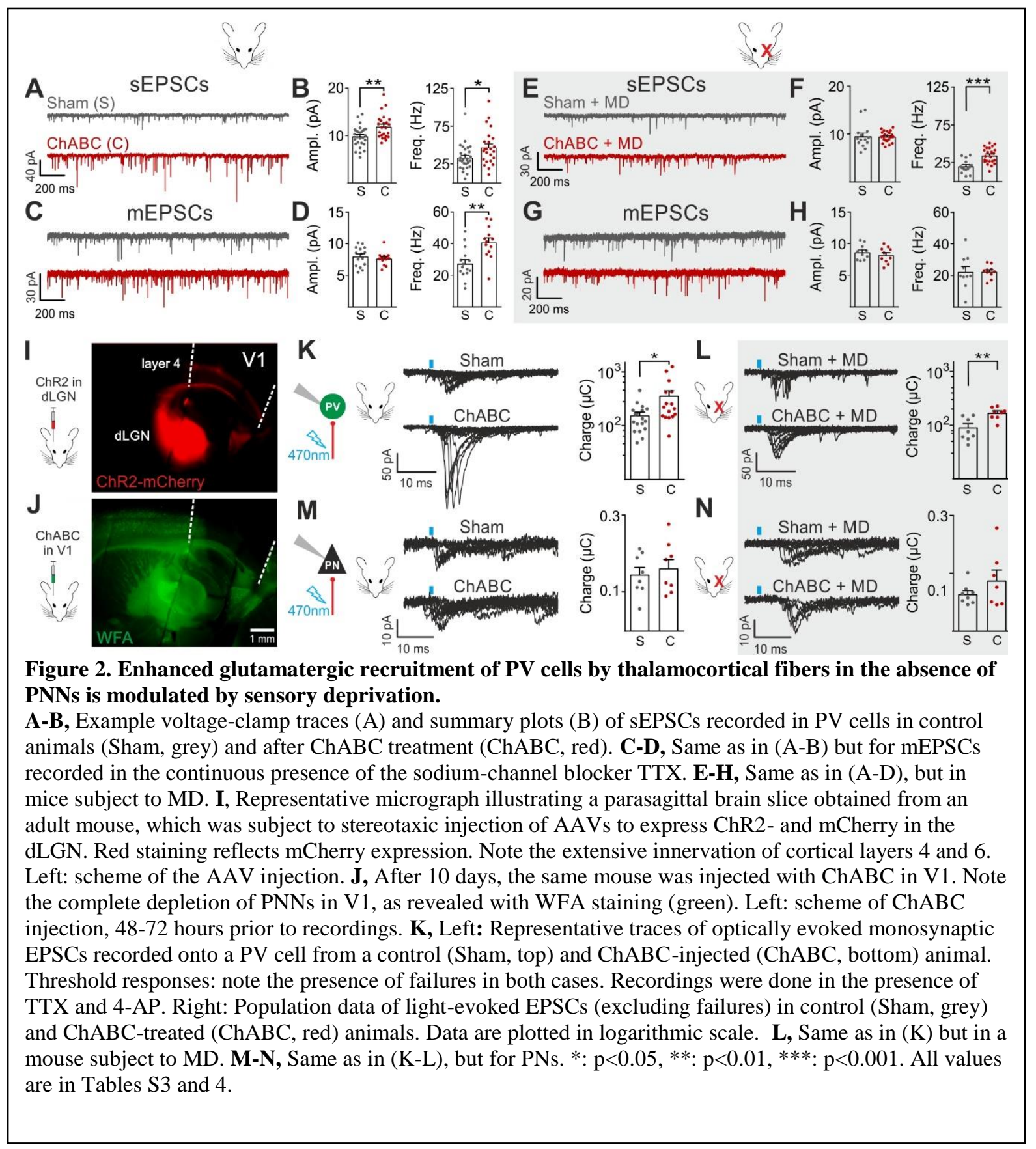


monosynaptic thalamocortical recruitment of PNs, both in the absence and presence of MD (Figure 2M,N; Table S4).

These results indicate that PNN accumulation controls the strength of thalamic glutamatergic synapses onto PV cells selectively, and this is forcibly modulated by visual activity.

\section{PNNs do not directly affect GABAergic synapses to and from PV cells.}

Cortical plasticity is strongly modulated by inhibition (Fagiolini et al., 2004;Hensch, 2005; Toyoizumi et al., 2013;Kuhlman et al., 2013). Accordingly, we found that removal of PNNs is consistent with a more strongly inhibited cortical network (Figure 1) (Sohal et al., 2009; Cardin et al., 2009; Atallah et al., 2012), and enhanced recruitment of PV cells (Figure 2). To test directly if PNN disruption in adult mice changed inhibitory synapses onto PV cells and PNs, we pharmacologically isolated spontaneous and miniature inhibitory postsynaptic currents (s- and mIPSCs), using a high-chloride intracellular solution, in the continuous presence of glutamate receptor antagonists (see Methods). We found that sIPSC amplitude and frequency onto PV cells were increased upon removal of PNNs (Figure 3A,B; Table S5). Interestingly, however, AP-independent quantal mIPSC transmission was not affected by PNN removal (Figure 3C,D; Table S5). These results indicate that spontaneous GABAergic transmission onto PV cells was due to a network effect, rather than a direct synaptic alteration. Plasticity induced by sensory deprivation prevented the ChABC-mediated increase of sIPSC amplitudes, whereas frequency was still increased in PNN-depleted mice (Figure 3E-H; Table S5). Importantly, we did not find any change in sIPSCs in PNs following 


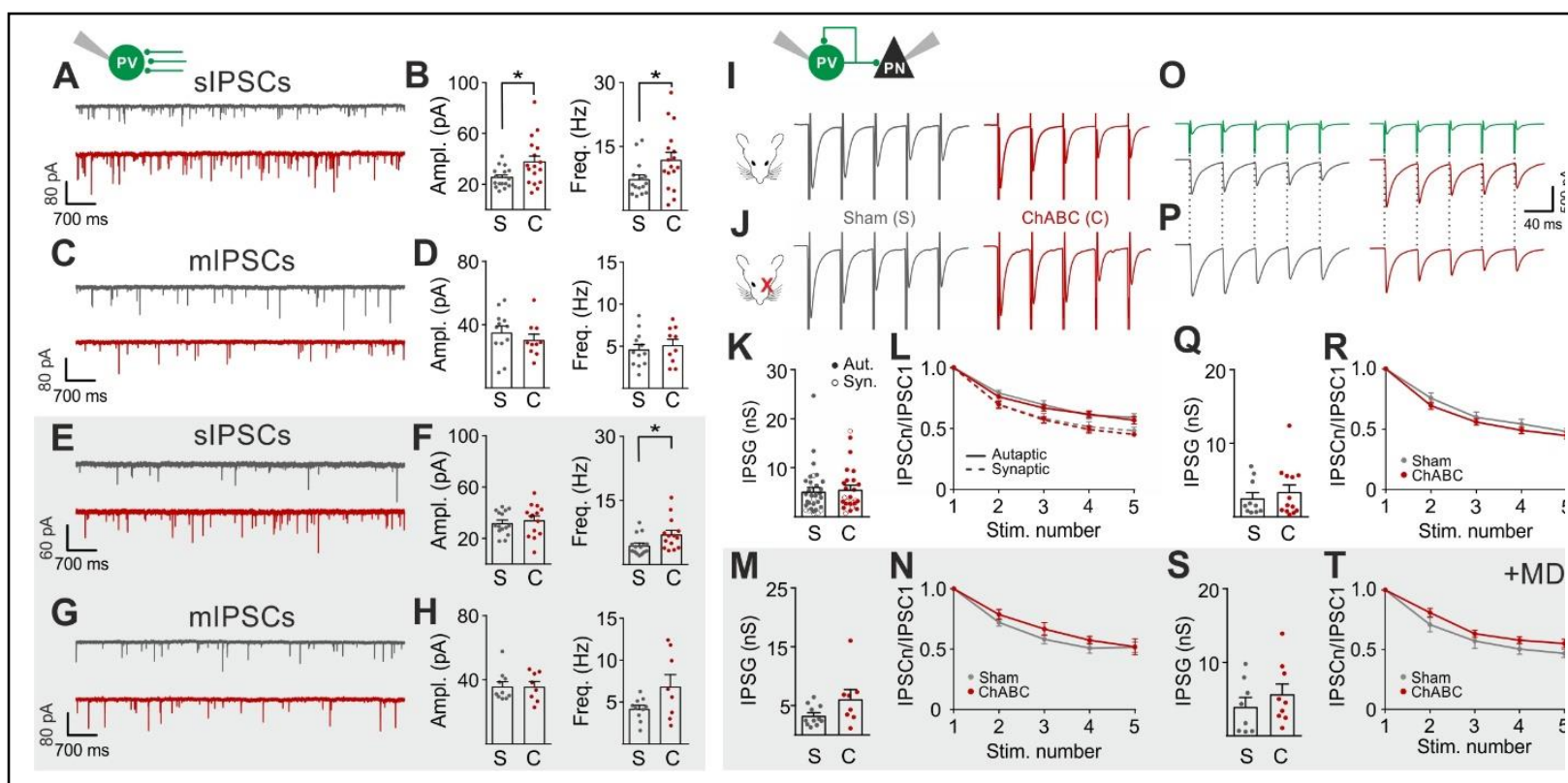

Figure 3. PNNs do not directly affect GABAergic synapses to and from PV cells.

A-B, Example voltage-clamp traces (A) and summary plots (B) of sIPSCs recorded in PV cells in control animals (Sham, grey) and after ChABC treatment (ChABC, red). C-D, Same as in (A-B) but for mIPSCs recorded in the continuous presence of the sodium-channel blocker TTX. s- and mIPSCs were pharmacologically isolated in the continuous presence of DNQX. E-H, Same as in (A-D), but in mice subject to MD. I-J, Example traces (average of 50 sweeps) of unitary autaptic IPSCs in PV cells from non-visually deprived animals (I) and following MD (J), in control (Sham, grey) and ChABC-injected mice (ChABC, red). K-N, Peak amplitude conductance $(\mathrm{K}, \mathrm{M})$ and short-term plasticity $(\mathrm{L}, \mathrm{N})$ of unitary PV-PV synaptic (opened circles) and autaptic (filled circles) connections in control (Sham, grey) and in ChABC-treated (ChABC, red) mice, in the absence $(\mathrm{k}, 1)$ and presence $(\mathrm{m}, \mathrm{n})$ of MD. Train frequency was $50 \mathrm{~Hz}$. Autaptic responses: filled lines; synaptic responses: dotted lines. O-T, Same as in (I-N), but for PV-PN uIPSCs. *: p<0.05. All values are in Tables S5 and 6.

ChABC injection, both in the absence and presence of MD (Figure S4E-H; Table S5). To

directly test whether local GABAergic synapses to and from PV cells were not affected by

PNN removal, we performed simultaneous recordings in PV-PV and PV-PN connected pairs, in the presence and absence of MD. In addition, PV-PV inhibitory connections were also examined as autaptic self-inhibiting responses, which are highly common in neocortical PV cells (Deleuze et al., 2014) (Figure S5). Overall, we found that PNN disruption did not alter unitary GABAergic transmission from PV cells onto themselves, other PV cells and PNs, in terms of magnitude and short-term plasticity, both in the absence and presence of MD (Figure 3I-T; Table S6).

Altogether, these results indicate that GABAergic synapses from PV cells onto PNs and other 
GABAergic spontaneous activity results from increased AP-dependent activity of interneurons.

\section{PNNs differently gate thalamocortical feed-forward inhibition on PV cells and PNs in a} visually dependent manner.

The results of Figures 2 and 3 suggest a selective and experience-dependent increase of thalamic excitatory neurotransmission onto PV cells in response to PNN removal, with no direct effect on quantal and unitary GABAergic responses. Thalamic activation of PV cells is very potent in neocortical L4 (Gabernet et al., 2005;Sun et al., 2006;Cruikshank et al., 2010;Bagnall et al., 2011), generating strong feed-forward inhibition (FFI), which is responsible for sharpening contrast sensitivity and controlling the temporal resolution of sensory integration(Gabernet et al., 2005). Importantly, PNN degradation affected contrast sensitivity (Figure 1) and AP-dependent sIPSCs onto PV cells (Figure 3). We therefore tested whether increased thalamic recruitment of PV cells affects disynaptic FFI in cortical L4. We isolated thalamic-induced FFI in both PV cells and PNs by activating ChR2-positive fibers at the reversal potential for glutamate-mediated responses, and in the absence of TTX and 4-AP (Figure 4A,B; Table S7; see Methods). We found that ChABC treatment strongly increased FFI in PV cells, elicited by threshold stimulations. Again, MD strongly attenuated this effect (Figure 4A,B, shaded area; size effect Glass' delta: 6.89 vs. 2.30; control vs. MD, respectively). Surprisingly, we did not detect any change of FFI on PNs, when measured at threshold (Figure 4C,D). Importantly, however, at a higher stimulus intensity (1.5 x threshold), FFI was significantly increased by ChABC treatment also in PNs, and sensory deprivation prevented FFI potentiation onto PNs (Figure 4E,F). 


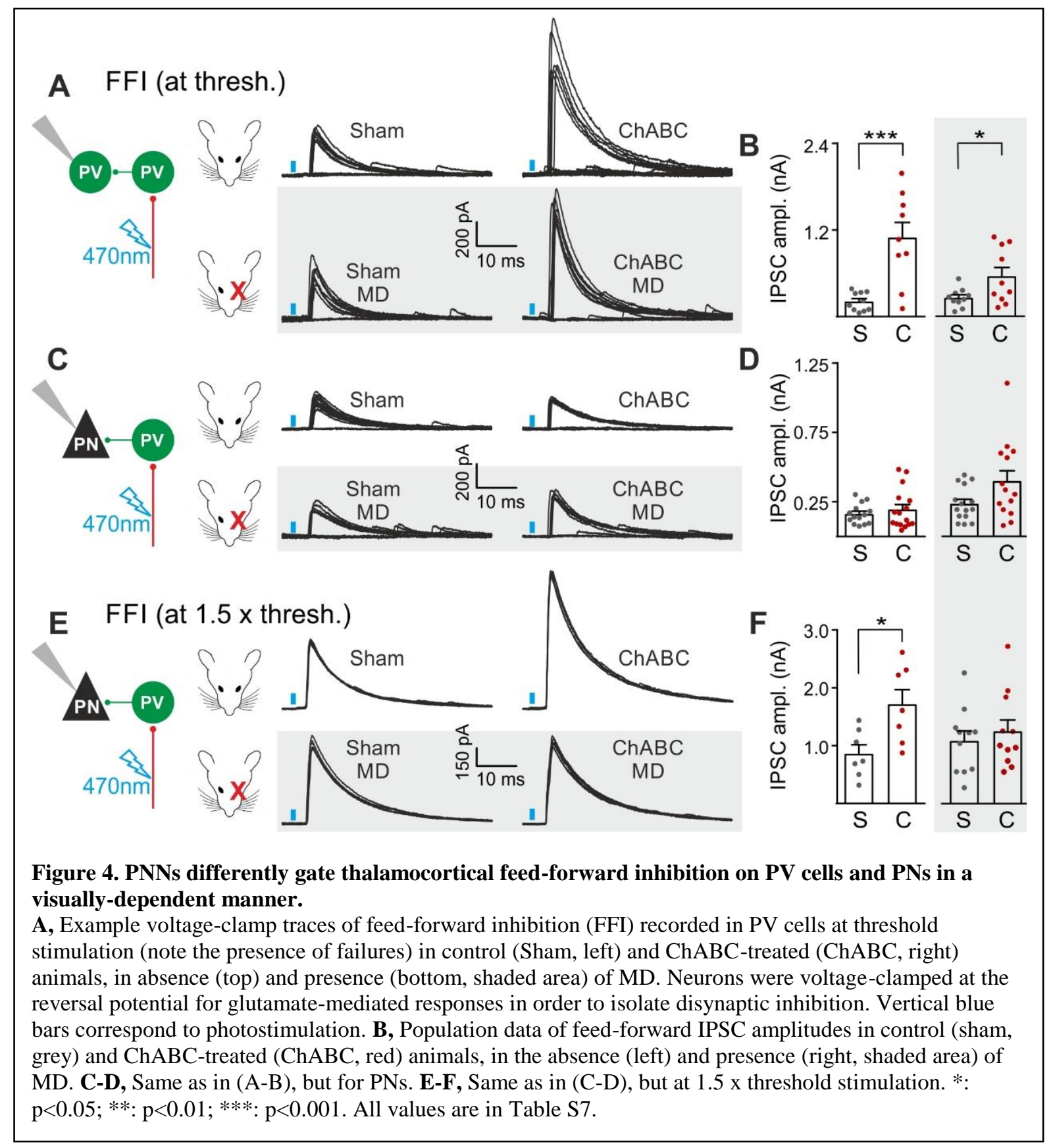

212 Altogether, these results indicate a preferential gating of disynaptic, feed-forward inhibition

213 in L4. Indeed, compared to PNs, FFI on PV cells was more sensitive to modulation by PNN

214 accumulation. In addition, the boost of FFI was strongly dependent on visual input, similarly

215 to s-, m-EPSCs and thalamocortical glutamatergic activation of PV cells. 


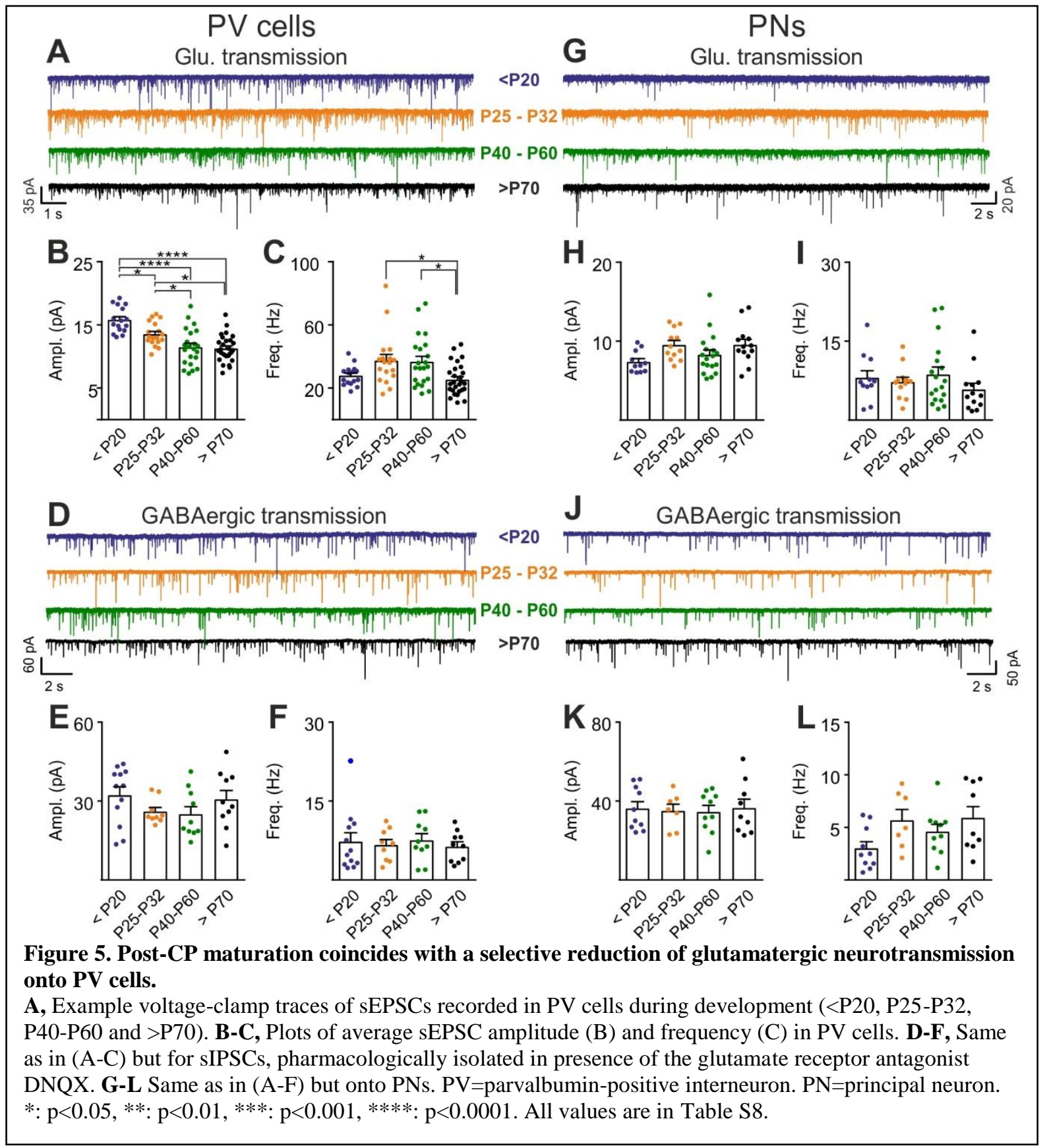

PNN accumulation in the visual system co-occurs with the end of the CP (P30-35)

(Pizzorusso et al., 2002). Importantly, PNN disruption in V1 of adult mice re-opens cortical

plasticity (Pizzorusso et al., 2002), and is associated to increased glutamatergic synaptic

transmission selectively in PV cells (Figure 2). We therefore measured glutamatergic and

GABAergic neurotransmission on PV cells and PNs before $(<\mathrm{P} 20)$, at the peak $(\mathrm{P} 25-32)$ and changes of the overall strength of glutamatergic neurotransmission onto PV cells. 
Interestingly, we found that the maturation of cortical circuits after the $\mathrm{CP}$ is accompanied by a decrease of glutamatergic neurotransmission onto PV cells (both sEPSC amplitudes and frequency; Figure 5A-C, Table S8), whereas GABAergic inhibition on PV cells was unchanged throughout development (Figure 5D-F, Table S8). This developmental decrease of glutamatergic strength was selective for PV cells, as both glutamatergic and GABAergic neurotransmissions on PNs were stable across pre- and post-CP stages (Figure 5G-L, Table S8).

These results suggest that the accumulation of PNNs around PV cells during post-CP development determines a change in the excitation-to-inhibition ratio in this interneuron type, and $\mathrm{ChABC}$-mediated disruption of PNNs in adult animals (Figure 2) recapitulates some juvenile features of visual cortical circuits.

\section{Discussion}

In this study, we demonstrate that PNNs modulate the gain of contrast sensitivity and network synchrony during cortical $\gamma$-oscillations. This is associated to a selective increase of thalamic glutamatergic recruitment of PV interneurons, without altering their excitability and the quantal properties of their GABAergic synapses. Increased thalamic recruitment of PV cells in the absence of PNNs strongly affects FFI differentially in PV cells and PNs (Figure 6A). All these effects are dependent on visual input, as they are reduced or prevented by sensory plasticity induced by MD (Fig 6B). Interestingly, selective decrease of glutamatergic neurotransmission onto PV cells is present during the post-CP development, which is paralleled by accumulation of PNNs around these interneurons.

Reduced gain of contrast sensitivity and increased power of $\gamma$-oscillations are consistent with increased activity of PV interneurons. Indeed, optogenetic activation of PV cells was shown 


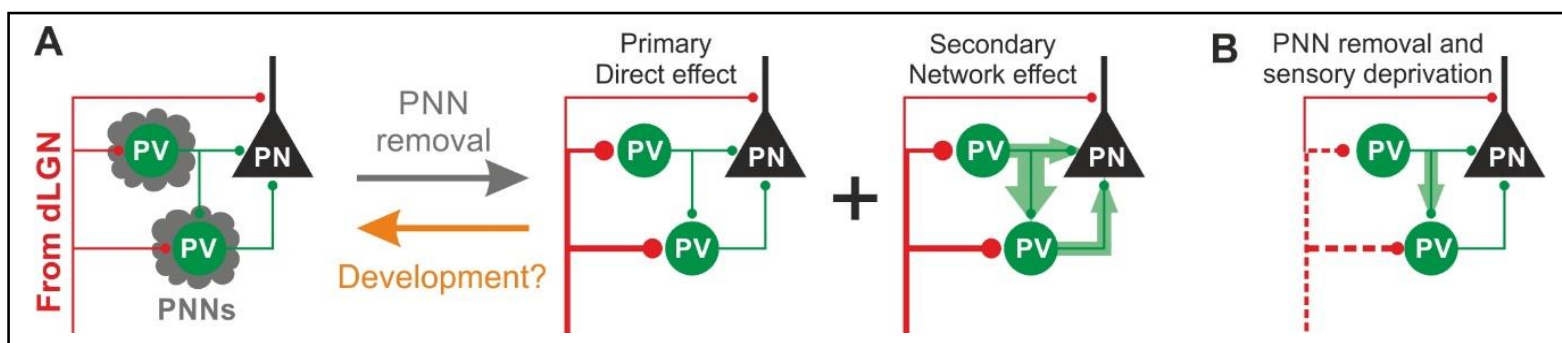

Figure 6. Schematic interpretation of the plastic synaptic and circuit effects induced by PNN removal and monocular deprivation in L4 of adult V1.

A, In normal adult mice, PV neurons are enwrapped by PNNs (grey). Both PV cells and PNs are contacted by thalamic fibers (red) and form local connections in L4 (green). ChABC injection (grey arrow) disrupts PNNs and induces a specific increase of the recruitment of PV cells by dLGN afferents, schematized by larger synapses (illustrated in red). This primary direct effect leads to a secondary network effect, namely an increase of feed-forward inhibition onto PV cells as well as onto PNs. Importantly, feed-forward inhibition onto PV cells is much stronger and more sensitive than on PNs, as represented by the width of green arrows. Our results on spontaneous transmission suggest that the impact of PNN degradation might re-capitulate younger stages (orange arrow). B, Plasticity induced by sensory deprivation (MD) in PNN-depleted animals manifests itself as strong reduction (dotted red lines) of the boost of PV-cell recruitment induced by PNN removal normalizing feed-forward inhibition onto PNs and reducing the increase of FFI onto PV cells.

to have a strong effect on the gain of visual contrast sensitivity (Atallah et al., 2012), and determine the level of $\gamma$-power and information transfer in the neocortex (Cardin et al., 2009; Sohal et al., 2009). Therefore, the PNN-dependent effects shown here are consistent with either increased PV-cell excitability and firing, and/or altered synaptic transmission to and from these cells. Indeed, it has been suggested that removal of PNNs in the adult results in alterations of AP waveform and firing (Dityatev et al., 2007;Balmer, 2016). In contrast, here we show that intrinsic excitability of PV cells and PNs is not affected by in vivo enzymatic digestion of PNNs in the adult visual cortex. This discrepancy could be due to different approaches used to remove or diminish the expression of PNNs: in vivo vs. in vitro digestion, or genetic downregulation. Indeed, acute in vitro digestion of PNNs might not entirely recapitulate the actual remodeling of cortical networks induced by visual input. In addition, genetic downregulation of brevican (Favuzzi et al., 2017), a key component of the extracellular matrix, could be prone to developmental and/or homeostatic processes that we did not induce here, due to the relatively short depletion of PNNs in adult animals.

Importantly, our approach was demonstrated to re-open visual plasticity in adult animals (Pizzorusso et al., 2002). 
Another important mechanism by which PNNs might limit cortical plasticity could be attributed to decreased inhibition from PV cells. A recent study suggest that reduced cortical GABAergic neurotransmission is responsible for unlocking juvenile plasticity in adult animals, although this was not tested directly, but inferred by spiking activity (Lensjo et al., 2017). In fact, here we show that network-induced FFI and AP-dependent spontaneous synaptic inhibitory neurotransmission were rather enhanced by PNN removal, although quantal and unitary GABAergic neurotransmission were not affected. These results strongly suggest that increased thalamic glutamatergic strength onto PV cells increases networkdependent FFI (Figure 6A). The enhanced thalamic recruitment of PV cells and the consequent network-driven increase of GABAergic transmission (Figure 4G-H) explain the reduction of the gain of contrast adaptation and the enhancement of $\gamma$-oscillations measured in vivo (Figure 1), as they are both consistent with increased activity of PV cells (Sohal et al., 2009; Cardin et al., 2009; Atallah et al., 2012).

Increased FFI onto PV cells and PNs was most likely due to a ChABC-mediated effect on PV-cell recruitment and not on unitary GABAergic responses, as they were not affected by PNN depletion, as shown in Figure 3. Interestingly, FFI on PV interneurons was much more sensitive to the presence of PNNs than FFI on PNs. This well agrees with the PV cell-specific modulation of sIPSCs by PNNs. The stronger sensitivity of FFI onto PV cells, could be due to the significantly stronger unitary PV-PV connections, as compared to PV-PN synapses $(\mathrm{P}<0.05)$. The preferential PNN-mediated alteration of FFI onto PV cells might favor L4 circuit disinhibition (and thus paradoxical excitation) for visual stimulations at low intensities, whereas FFI on PNs becomes more prominent at stronger visual stimuli, thus reducing the gain of the visual adaptation curve (Figure 1). Moreover, PNN-dependent modulation of FFI in L4 might affect spike-timing precision of both PV cells and PNs, and 
change the integration window during the initial steps of sensory processing (Gabernet et al., 2005).

The increased glutamatergic recruitment of PV cells induced by PNN degradation could result from alterations induced in the pre- or postsynaptic site (or both). Our optogenetic approach does not allow dissecting the precise synaptic site affected by PNN degradation. This is especially true for the protocol used to isolate thalamocortical inputs onto PV cells and PNs, which is nonetheless useful to prevent unwanted multi-synaptic activity, typical of these powerful synapses(Petreanu et al., 2009), but it compromises the analysis of presynaptic release probability. The increase of mEPSC frequency but not amplitude on PV cells, induced by PNN degradation, suggests a presynaptic modulation. Yet, future experiments will be necessary to unequivocally determine whether the absence of PNNs alters thalamic synapses via pre- or postsynaptic mechanisms.

Our MD results demonstrate that the potentiated thalamic recruitment in the absence of PNNs depends on visual activity. A small, albeit significant, reduction of PV-cell and PN recruitment induced by sensory deprivation in adult mice is present also in control conditions $(P<0.05$; not shown), suggesting that 2-3 days of MD are sufficient to slightly downregulate contralateral thalamic input in the binocular cortex. However, in the absence of PNNs, MD effects are more pronounced. Therefore, we conclude that the MD-dependent reduction of PV-cell recruitment is likely the mechanism that is responsible for re-opening adult cortical plasticity following PNN degradation(Pizzorusso et al., 2002). Interestingly, this effect is similar to that occurring in young animals during the $\mathrm{CP}$, in which sensory deprivation reduces the firing rate of PV cells due to a decrease of synaptic excitatory drive onto these interneurons (Kuhlman et al., 2013). Accordingly, we found a significant reduction of glutamatergic synaptic strength selectively on PV cells, during a post-CP maturation window that is paralleled by enrichment of PNNs around PV cells. The lack of changes of the 
inhibitory strength during the post-CP development suggest that the accumulation of PNNs is associated to a change in the excitatory-to-inhibitory ratio only onto PV cells, and that might be responsible for the closure of cortical plasticity in the adult.

We conclude that PNN accumulation during post-CP development might exert a protective role, selectively dampening thalamic excitation of PV cells (and thus excessive cortical circuit inhibition) at the expense of reducing cortical plasticity. Age-dependent reduction of plasticity of thalamic synapses onto PV cells might be thus instrumental for correct mature sensory representation. Accordingly, deficits in PNN formation during development have been associated with brain diseases involving altered sensory perception, such as schizophrenia and autism (Sorg et al., 2016).

\section{Supplemental Information}

Supplemental Information includes six figures and eight tables

Acknowledgments We thank Joana Lourenço and Javier Zorrilla de San Martin for crucial help during the execution of this project and for critically reading this manuscript. We thank Giovanni Marsicano and Laurence Cathala for critically reading this manuscript. We are grateful to all members of the Bacci laboratory for help and suggestions and to Didi Lamers for participating to some in vivo experiments in Pisa.

This work was supported by European Research Council (ERC) under the European Community's 7th Framework Programmme (FP7/2007-2013)/ERC grant agreement No 200808); “Investissements d'avenir" ANR-10-IAIHU-06; Agence Nationale de la Recherche (ANR-13-BSV4-0015-01, ANR-FRONTELS, ANR-NanoSynDiv), Fondation Recherche Médicale (Equipe FRM DEQ20150331684; FDT20160435199), NARSAD independent 
investigator grant, and a grant from the Institut du Cerveau et de la Moelle épinière (Paris) (A.B.). Telethon grants GGP13187 and GGP12265 to G.M.R and flagship project Nanomax to G.M.R.

Author contributions G.F., C.D., T.P., G.M.R. and A.B. designed the experiments; G.F. performed all slice experiments, surgical procedures, immunohistochemistry and analyses; A.A. performed surgical procedures and immunohistochemistry; T.P. provided the initial idea, and contributed steering the project; S.L. and G.R. designed and performed the experiments and analyses in vivo; C.D. set up the initial experiments and co-supervised the project; A.B. supervised the project; A.B. and G.F. wrote the manuscript with input from all authors.

\section{Declaration of interests}

The authors declare no competing interests.

\section{References}

Anderson,J.S., Lampl,I., Gillespie,D.C., and Ferster,D. (2000). The contribution of noise to contrast invariance of orientation tuning in cat visual cortex. Science 290, 1968-1972. Atallah,B.V., Bruns,W., Carandini,M., and Scanziani,M. (2012). Parvalbumin-expressing interneurons linearly transform cortical responses to visual stimuli. Neuron 73, 159-170. Bagnall,M.W., Hull,C., Bushong,E.A., Ellisman,M.H., and Scanziani,M. (2011). Multiple Clusters of Release Sites Formed by Individual Thalamic Afferents onto Cortical Interneurons Ensure Reliable Transmission. 71, 180-194.

Balmer,T.S. (2016). Perineuronal Nets Enhance the Excitability of Fast-Spiking Neurons. eNeuro. 3.

Berardi,N., Pizzorusso,T., and Maffei,L. (2004). Extracellular matrix and visual cortical plasticity: freeing the synapse. Neuron 44, 905-908. 
Bernard,C., and Prochiantz,A. (2016). Otx2-PNN Interaction to Regulate Cortical Plasticity. Neural Plast. 2016, 7931693.

Bradbury,E.J., Moon,L.D., Popat,R.J., King,V.R., Bennett,G.S., Patel,P.N., Fawcett,J.W., and McMahon,S.B. (2002). Chondroitinase ABC promotes functional recovery after spinal cord injury. Nature 416, 636-640.

Buzsaki,G., and Wang,X.J. (2012). Mechanisms of gamma oscillations. Annu. Rev. Neurosci. 35, 203-225.

Carandini,M., and Ferster,D. (1997). A tonic hyperpolarization underlying contrast adaptation in cat visual cortex. Science 276, 949-952.

Cardin,J.A., Carlen,M., Meletis,K., Knoblich,U., Zhang,F., Deisseroth,K., Tsai,L.H., and Moore,C.I. (2009). Driving fast-spiking cells induces gamma rhythm and controls sensory responses. Nature 459, 663-667.

Cohen,J. (1988). Statistical Power Analysis for the Behavioral Sciences Academic Press).

Coleman,J.E., Nahmani,M., Gavornik,J.P., Haslinger,R., Heynen,A.J., Erisir,A., and Bear,M.F. (2010). Rapid structural remodeling of thalamocortical synapses parallels experience-dependent functional plasticity in mouse primary visual cortex. J. Neurosci. 30, 9670-9682.

Cruikshank,S.J., Urabe,H., Nurmikko,A.V., and Connors,B.W. (2010). Pathway-specific feedforward circuits between thalamus and neocortex revealed by selective optical stimulation of axons. Neuron 65, 230-245.

de,V.L., Landi,S., Panniello,M., Baroncelli,L., Chierzi,S., Mariotti,L., Spolidoro,M., Pizzorusso,T., Maffei,L., and Ratto,G.M. (2013). Extracellular matrix inhibits structural and functional plasticity of dendritic spines in the adult visual cortex. Nat. Commun. 4, 1484.

Deleuze,C., Pazienti,A., and Bacci,A. (2014). Autaptic self-inhibition of cortical GABAergic neurons: Synaptic narcissism or useful introspection? Curr. Opin. Neurobiol. 26C, 64-71.

Dityatev,A., Bruckner,G., Dityateva,G., Grosche,J., Kleene,R., and Schachner,M. (2007). Activity-dependent formation and functions of chondroitin sulfate-rich extracellular matrix of perineuronal nets. Dev. Neurobiol. 67, 570-588.

Donato,F., Rompani,S.B., and Caroni,P. (2013). Parvalbumin-expressing basket-cell network plasticity induced by experience regulates adult learning. Nature 504, 272-276.

Espinosa,J.S., and Stryker,M.P. (2012). Development and plasticity of the primary visual cortex. Neuron 75, 230-249.

Fagiolini,M., Fritschy,J.M., Low,K., Mohler,H., Rudolph,U., and Hensch,T.K. (2004). Specific GABAA circuits for visual cortical plasticity. Science 303, 1681-1683.

Favuzzi,E., Marques-Smith,A., Deogracias,R., Winterflood,C.M., Sanchez-Aguilera,A., Mantoan,L., Maeso,P., Fernandes,C., Ewers,H., and Rico,B. (2017). Activity-Dependent Gating of Parvalbumin Interneuron Function by the Perineuronal Net Protein Brevican. Neuron 95, 639-655. 
Freund,T.F., and Katona,I. (2007). Perisomatic inhibition. Neuron 56, 33-42.

Gabernet,L., Jadhav,S.P., Feldman,D.E., Carandini,M., and Scanziani,M. (2005).

Somatosensory integration controlled by dynamic thalamocortical feed-forward inhibition.

Neuron 48, 315-327.

Gherardini,L., Gennaro,M., and Pizzorusso,T. (2015). Perilesional treatment with chondroitinase $\mathrm{ABC}$ and motor training promote functional recovery after stroke in rats. Cereb. Cortex 25, 202-212.

Glass,G.V., McGaw,B., and Smith,M.L. (1981). Meta-Analysis in Social Research Sage Library of Social Research).

Gogolla,N., Caroni,P., Luthi,A., and Herry,C. (2009). Perineuronal nets protect fear memories from erasure. Science 325, 1258-1261.

Gogolla,N., Takesian,A.E., Feng,G., Fagiolini,M., and Hensch,T.K. (2014). Sensory integration in mouse insular cortex reflects GABA circuit maturation. Neuron 83, 894-905.

Hensch,T.K. (2005). Critical period plasticity in local cortical circuits. Nat. Rev. Neurosci. 6, $877-888$

Hensch,T.K., and Fagiolini,M. (2005). Excitatory-inhibitory balance and critical period plasticity in developing visual cortex. Prog. Brain Res. 147, 115-124.

Hubener,M., and Bonhoeffer,T. (2014). Neuronal plasticity: beyond the critical period. Cell 159, 727-737.

Isaacson,J.S., and Scanziani,M. (2011). How inhibition shapes cortical activity. Neuron 72, 231-243.

Jaepel,J., Hubener,M., Bonhoeffer,T., and Rose,T. (2017). Lateral geniculate neurons projecting to primary visual cortex show ocular dominance plasticity in adult mice. Nat. Neurosci. 20, 1708-1714.

Kloc,M., and Maffei,A. (2014). Target-specific properties of thalamocortical synapses onto layer 4 of mouse primary visual cortex. J. Neurosci. 34, 15455-15465.

Kuhlman,S.J., Olivas,N.D., Tring,E., Ikrar,T., Xu,X., and Trachtenberg,J.T. (2013). A disinhibitory microcircuit initiates critical-period plasticity in the visual cortex. Nature 501, 543-546.

Lakens,D. (2013). Calculating and reporting effect sizes to facilitate cumulative science: a practical primer for t-tests and ANOVAs. Front Psychol. 4, 863.

Lensjo,K.K., Lepperod,M.E., Dick,G., Hafting,T., and Fyhn,M. (2017). Removal of Perineuronal Nets Unlocks Juvenile Plasticity Through Network Mechanisms of Decreased Inhibition and Increased Gamma Activity. J. Neurosci. 37, 1269-1283.

Manseau,F., Marinelli,S., Mendez,P., Schwaller,B., Prince,D.A., Huguenard,J.R., and Bacci,A. (2010). Desynchronization of Neocortical Networks by Asynchronous Release of GABA at Autaptic and Synaptic Contacts from Fast-Spiking Interneurons. PLoS. Biol. 8. 
441 Marin,O. (2012). Interneuron dysfunction in psychiatric disorders. Nat. Rev. Neurosci. 13, $442 \quad 107-120$.

443 Petreanu,L., Mao,T., Sternson,S.M., and Svoboda,K. (2009). The subcellular organization of neocortical excitatory connections. Nature 457, 1142-1145.

Pizzorusso,T., Medini,P., Berardi,N., Chierzi,S., Fawcett,J.W., and Maffei,L. (2002). Reactivation of ocular dominance plasticity in the adult visual cortex. Science 298, 12481251.

Sohal,V.S., Zhang,F., Yizhar,O., and Deisseroth,K. (2009). Parvalbumin neurons and gamma rhythms enhance cortical circuit performance. Nature 459, 698-702.

Sorg,B.A., Berretta,S., Blacktop,J.M., Fawcett,J.W., Kitagawa,H., Kwok,J.C., and Miquel,M. (2016). Casting a Wide Net: Role of Perineuronal Nets in Neural Plasticity. J. Neurosci. 36, 11459-11468.

Sun,Q.Q., Huguenard,J.R., and Prince,D.A. (2006). Barrel cortex microcircuits: thalamocortical feedforward inhibition in spiny stellate cells is mediated by a small number of fast-spiking interneurons. J. Neurosci. 26, 1219-1230.

Takesian,A.E., Bogart,L.J., Lichtman,J.W., and Hensch,T.K. (2018). Inhibitory circuit gating of auditory critical-period plasticity. Nat. Neurosci. 21, 218-227. Miller,K.D. (2013). A theory of the transition to critical period plasticity: inhibition selectively suppresses spontaneous activity. Neuron 80, 51-63. Cellular Properties to Circuits. Neuron 91, 260-292. 


\section{Methods}

\section{Animals}

Experimental procedures followed National and European guidelines, and have been approved by the authors' institutional review boards (French Ministry of Research and Innovation and Italian Ministry of Health). In order to identify GABAergic transmission from PV interneurons we used PV-Cre mice (Jackson Laboratory Stock Number 008069). To selectively express EGFP in PV-positive cells, we bred PV:Cre with RCE:loxP (kindly provided by Gordon Fishell, New York University), obtaining PV-Cre::RCE mice. Male mice of different postnatal age groups were used, recapitulating developmental stages and accumulation of PNNs around PV cells: < P20 (before the CP), P25-P32 (CP), P40-P60 (maturation of PNNs) and > P70 (adult). In vivo experiments were performed on adult C57BL/6J mice older than P70 (Jackson Laboratory stock number 000664). All mice used in the study were reared in a 12 hours light/dark cycle with food ad libitum.

\section{In vivo enzymatic degradation of PNNs in $\mathrm{V} 1$}

To disrupt PNNs locally in V1, adult mice underwent a stereotaxic injection of the bacterial enzyme chondroitinase $\mathrm{ABC}$ (ChABC) from Proteus vulgaris (Sigma) or of the phosphate-buffered saline solution (PBS - control). ChABC was prepared beforehand: the powder was reconstituted in $0.01 \%$ bovine serum albumin aqueous solution for a final concentration of $100 \mathrm{mU} / \mathrm{mL}$. Before each injection, reconstituted ChABC was diluted in a second buffer containing $50 \mathrm{mM}$ Tris, $60 \mathrm{mM}$ sodium acetate and $0.02 \%$ bovine serum albumin $(\mathrm{pH}=8.0)$ in order to obtain a final concentration of $40 \mathrm{U} / \mathrm{mL}$. Adult mice were placed in an anesthesia induction cage $(3 \%$ isoflurane Iso-Vet@; $250 \mathrm{~mL}$ air) until insensitive to nociceptive stimuli (tail pinch) and then fixed on a stereotaxic apparatus with a mouth mask constantly delivering isoflurane $(2-2.5 \%$ isoflurane; $200 \mathrm{~mL}$ air). The analgesic buprenorphine $\left(0.1 \mathrm{mg} / \mathrm{kg}\right.$ - Buprecare $\left.{ }^{\circledR}\right)$ was intraperitoneally injected and an ophthalmic ointment was applied on the eyes. Body temperature was constantly controlled and maintained to $37.5^{\circ}$ using a heating pad. An incision was done in the skin (the local anesthetic bupivacaine was applied before the incision; $0.25 \%$ in $\mathrm{NaCl} 0.9 \%$ ) and a small hole was drilled in one hemisphere at $2.9 \mathrm{~mm}$ lateral from Lambda. Small glass capillaries (external diameter of $40 \mu \mathrm{m}$; internal diameter of $60 \mu \mathrm{m}$ ), beveled in order to ensure a better penetration into the tissue and therefore produce less damages, were filled with $1 \mu \mathrm{L}$ ChABC or PBS. Two injections of $350 \mathrm{~nL}$ each (with a rate of $100 \mathrm{~nL} / \mathrm{min}$ ) were realized at a depth of $800 \mu \mathrm{m}$ and then $400 \mu \mathrm{m}$, with $5 \mathrm{~min}$ of interval. The skin was sutured with a non-absorbable 3/0 filament (Ethicon®), an antiseptic (betadine) was applied on the skin and the mouse gently removed from the frame and kept at $37^{\circ} \mathrm{C}$ in a heated chamber until full recovery. In vivo experiments or brain slices for electrophysiology were prepared 2-3 days post-injection.

\section{In vivo expression of the light-sensitive channel ChR2 in the dLGN}

The thalamocortical (TC) pathway was studied by an optogenetic approach: the light-sensitive opsin channelrodopsin-2 (ChR2) was expressed on the membrane of glutamatergic neurons in thalamic dorsolateral geniculate nucleus (dLGN) of adult mice. ChR2 was transduced by stereotaxic injections of an adeno-associated (AAV) virus, expressing ChR2 under the promoter of the calcium/calmodulin dependent protein kinase II (CaMKII) (AAV9.CaMKIIa.hChR2(H134R)-mCherry.WPRE.hGH; Addgene\#: 20297, Penn Vector Core, University of Pennsylvania). Viral particles were injected in the hemisphere, in which PNNs were subsequently 
degraded. The procedure was similar to the ChABC/PBS injections (see section above) except for the following points: $i$ ) we used a rigid needle (Hamilton ${ }^{\circledR}, 33$-gauge, $13 \mathrm{~mm}$, pst $4-20^{\circ}$ ), which is more appropriate to target deep structures such as the $\mathrm{dLGN}$; ii) the coordinates of injection site were $2.06 \mathrm{~mm}$ posterior to Bregma $-2 \mathrm{~mm}$ lateral to midline $-3.2 \mathrm{~mm}$ deep from the surface of the skull; iii) one $50 \mathrm{~nL}$ injection was performed at a rate of $50 \mathrm{~nL} / \mathrm{min}$ (viral titer: $2.5 \times 10^{13}$ particles $/ \mathrm{mL}$, diluted at a factor 5 in fresh PBS). After 10-12 days, sufficient for an adequate expression of $\mathrm{ChR} 2$, mice were treated with the ChABC or PBS injections. In some cases, mice were monocularly deprived as described below.

\section{Sensory deprivation in adult mice by monocular deprivation}

In some experiments, following the injection of ChABC/PBS, the eyelid of the left eye (contralateral to the injected hemisphere) was sutured shut. The anti-inflammatory Diprosone ( $0.05 \%$ ointment) was applied on the eye and the superior and inferior eyelids were gently removed with fine scissors. Four stitches were realized with non-absorbable 6/0 filament (Ethicon®). 1-2 drops of the anti-inflammatory Tobradex were put in the suturedeye and the mouse was removed from the frame and kept at $37^{\circ} \mathrm{C}$ in a heated chamber until full recovery. Mice were killed when signs of infection were observed or if the sutured eye re-opened. Brain slices for electrophysiology were prepared 48 to 72 hours post treatment and surgery.

\section{In vivo recordings}

During surgery and recordings, body temperature was maintained constant through a heating pad and respiration and heartbeat were monitored (heart rate range $420-580 \mathrm{bpm}$ ). Oxygen-enriched air was administered through all procedures. All necessary efforts were made to minimize the stress of the animals.

Mice were anesthetized by intraperitoneal injection of urethane $(0.8 \mathrm{ml} / \mathrm{kg}$ in $0.9 \% \mathrm{NaCl}$; Sigma $)$ and head restrained during the duration of the recordings. When necessary, $10 \%$ of initial dose were administered intraperitoneally to maintain the anesthetic level. A portion of the skull overlying the visual cortex $(0.0 \mathrm{~mm}$ anteroposterior and $2.9 \mathrm{~mm}$ lateral to the lambda suture) was drilled and the dura mater was left intact. A chamber was created with a thin layer of a dental cement around the edges of the craniotomy. Cortex was maintained constantly wet with ACSF containing (in $\mathrm{mM}$ ): $120 \mathrm{NaCl}, 3.2 \mathrm{KCl}, 2 \mathrm{CaCl}_{2}, 1 \mathrm{MgCl}_{2}, 1 \mathrm{~K}_{2} \mathrm{HPO}_{4}, 10 \mathrm{HEPES}$, $26 \mathrm{NaHCO}_{3},(\mathrm{pH}=7.4)$. Animals deeply anesthetized under urethane were sacrificed by cervical dislocation without regaining consciousness at the end of the experiment. Local field potentials (LFPs) and visually evoked potentials (VEPs) were recorded by a glass micropipette (impedance $\sim 2 \mathrm{M} \Omega$, filled with ACSF solution) positioned into the visual cortex at a depth of 250-300 $\mu \mathrm{m}$. A common reference $\mathrm{Ag}-\mathrm{AgCl}$ electrode was placed on the cortical surface in the ACSF bath. Electrophysiological signals were amplified 1000-fold (EXT-02F, NPI), band pass filtered $(0.1-1000 \mathrm{~Hz}$ ), and sampled at $2 \mathrm{kHz}$. Visual stimuli were generated on a LCD display (mean luminance at maximum contrast, $3 \mathrm{~cd} / \mathrm{m}^{2}$ ) by a MATLAB custom program that exploits the Psychophysics Toolbox, and the luminance of the stimuli was calibrated by means of a radiometer (Konica Minolta). Transient VEPs were recorded in response to the reversal of a checkerboard every 2 seconds (spatial frequency $0.04 \mathrm{c} / \mathrm{deg}$ ). The response to a blank stimulus ( $0 \%$ contrast) was also recorded to estimate noise. 


\section{Preparation of acute slices for electrophysiology}

In order to record intrinsic and synaptic properties of L4 neurons of V1, we prepared acute cortical slices from mice at different postnatal (P) ages ( $<$ P20; P25-P32; P40-P60 and $>$ P70), and adult ( $>$ P70) mice previously injected with either PBS (sham) or ChABC. For these experiments, we used slices cut in the sagittal plane (350 $\mu \mathrm{m}$ thick). In experiments from deprived-animals as well as in which thalamocortical neurons expressed $\mathrm{ChR} 2$, we cut slices in the coronal plane ( $350 \mu \mathrm{m}$ thick), to localize the binocular zone of V1 (V1b). Animals older than 25 days were subject to intracardial perfusion of ice-cold cutting solution (see below) before extracting the brain. This procedure improved the quality of slices and preserved the integrity of the tissue significantly. Animals were deeply anesthetized with pentobarbital (50mg/kg - Euthasol ${ }^{\circledR}$ Vet) and $100 \mu \mathrm{L}$ of Choay heparine was injected in the left ventricle of the heart before perfusion. Animals were then perfused through the heart with a choline-based cutting solution containing the following (in $\mathrm{mM}$ ): 126 choline chloride, 16 glucose, $26 \mathrm{NaHCO}_{3}, 2.5 \mathrm{KCl}, 1.25$ $\mathrm{NaH}_{2} \mathrm{PO}_{4}, 7 \mathrm{MgSO}_{4}, 0.5 \mathrm{CaCl}_{2}$, cooled to $4{ }^{\circ} \mathrm{C}$ and equilibrated with $95 \% \mathrm{O}_{2} / 5 \% \mathrm{CO}_{2}$. The brain was then quickly removed (for groups of mice aged $<\mathrm{P} 20$, this procedure started right after deep anesthesia) and immersed in the same cutting choline-based solution $\left(4^{\circ} \mathrm{C}\right.$, equilibrated with $\left.95 \% \mathrm{O}_{2} / 5 \% \mathrm{CO}_{2}\right)$. Slices were cut with a vibratome (Leica VT1200S) in cutting solution and then incubated in oxygenated artificial cerebrospinal fluid (aSCF) composed of (in mM): $126 \mathrm{NaCl}, 20$ glucose, $26 \mathrm{NaHCO}_{3}, 2.5 \mathrm{KCl}, 1.25 \mathrm{NaH}_{2} \mathrm{PO}_{4}, 1 \mathrm{MgSO}_{4}, 2 \mathrm{CaCl}_{2}$ (pH 7.35, $310-320 \mathrm{mOsm} / \mathrm{L}$ ), initially at $34^{\circ} \mathrm{C}$ for $30 \mathrm{~min}$, and subsequently at room temperature, before being transferred to the recording chamber where recordings were obtained at $30-32^{\circ} \mathrm{C}$.

\section{Slice electrophysiology and optogenetic stimulation}

Whole-cell patch-clamp recordings were performed in L4 of the primary visual cortex neurons V1. In MD animals, cells were patched in the binocular portion V1b. Inhibitory PV-expressing interneurons, labeled with GFP, were identified using LED illumination (OptoLED, blue, $\lambda=470 \mathrm{~nm}$, Cairn Research, Faversham, UK) and by their typical fast-spiking firing behavior in response to depolarizing DC current steps. Excitatory principal neurons (PNs) were visually identified using infrared video microscopy by their relatively small size round cell body and no apical dendrites. Accordingly, when depolarized with DC current pulses PNs exhibited a typical firing pattern of regular-spiking cells. We used different intracellular solutions depending on the type of experiment and the nature of the responses we wanted to assess. To study intrinsic excitability, AP waveform and glutamatergic spontaneous transmission, electrodes were filled with an intracellular solution containing (in $\mathrm{mM}$ ): $127 \mathrm{~K}$-gluconate, $6 \mathrm{KCl}, 10$ Hepes, 1 EGTA, $2 \mathrm{MgCl}$, 4 Mg-ATP, $0.3 \mathrm{Na}$-GTP; pH adjusted to 7.3 with KOH; 290-300 mOsm. The estimated reversal potential for chloride $\left(\mathrm{E}_{\mathrm{Cl}}\right)$ was approximately $-69 \mathrm{mV}$ based on the Nernst equation. To measure GABAergic currents (both sIPSCs and uIPSCs in paired recordings), neurons were recorded using an intracellular solution containing (in mM): $65 \mathrm{~K}$-gluconate, $70 \mathrm{KCl}, 10 \mathrm{Hepes}, 1 \mathrm{EGTA}, 2 \mathrm{MgCl} 2,4 \mathrm{Mg}$ ATP, $0.3 \mathrm{Na}$-GTP; pH adjusted to 7.3 with $\mathrm{KOH} ; 290-300 \mathrm{mOsm}$. The estimated $\mathrm{E}_{\mathrm{Cl}}$ was approximately $-16 \mathrm{mV}$ based on the Nernst equation. Under these recording conditions, activation of $\mathrm{GABA}_{\mathrm{A}}$ receptors resulted in inward currents at a holding potential $\left(\mathrm{V}_{\mathrm{h}}\right)$ of $-70 \mathrm{mV}$. Experiments using optical stimulation of ChR2-positive thalamocortical fibers were done with a cesium-based intracellular solution containing (in $\mathrm{mM}$ ): $125 \mathrm{CsMeSO}_{3}$, $3 \mathrm{CsCl}, 10$ Hepes, 5 EGTA, $2 \mathrm{MgCl}_{2}$, 4 Mg-ATP, $0.3 \mathrm{Na}-\mathrm{GTP}, 5 \mathrm{QX} 314-\mathrm{Cl}$; pH adjusted to 7.3 with CsOH; 290$300 \mathrm{mOsm}$. This solution allowed voltage-clamping neurons at various membrane potentials. $\mathrm{E}_{\mathrm{Cl}}$ - was approximately $-63 \mathrm{mV}$ based on the Nernst equation. Voltage values were not corrected for liquid junction 
potential. Patch electrodes were pulled from borosilicate glass capillaries and had a typical tip resistance of 2-3 M $\Omega$. Signals were amplified with a Multiclamp 700B patch-clamp amplifier (Molecular Devices), sampled at 20$50 \mathrm{KHz}$ and filtered at $4 \mathrm{KHz}$ (for voltage-clamp experiments) and $10 \mathrm{KHz}$ (for current-clamp experiments). Signals were digitized with a Digidata 1440A and acquired, using the pClamp 10 software package (Molecular Devices).

For intrinsic excitability experiments, neurons were recorded in current-clamp mode. In order to avoid any contribution of differences and variations in the membrane resistance $\left(\mathrm{R}_{\mathrm{m}}\right)$ on the frequency-current curves, the injected current was adjusted in each cell as a function of $R_{m}$. This value was determined by the Ohm's law (I= $\Delta \mathrm{V} / \mathrm{R}_{\mathrm{m}}$ ): we injected an amount of current (I) to obtain a $\Delta \mathrm{V}$ of $\sim 10 \mathrm{mV}$, depending on the actual $\mathrm{R}_{\mathrm{m}}$ of each cell, and increasing the amount of depolarizing current to obtain a $\Delta \mathrm{V}$ of $5 \mathrm{mV}$, for a total of 15 current steps. Single AP were obtained by injecting brief $(2 \mathrm{~ms}$ ) current steps of increasing amplitude from a Vm of $\sim-70 \mathrm{mV}$ in order to determine the minimal current intensity required to elicit a spike in each cell. This current was then injected 20 times and we averaged the trials for each cell from which we calculated the first derivative of the Vm and constructed planar phase plots to extract AP threshold values.

Synaptic events were recorded in voltage clamp mode for at least 2-3 minutes. EPSCs (spontaneous and miniatures) were isolated by clamping the cells at $-70 \mathrm{mV}$, using an intracellular solution containing $\left[\mathrm{Cl}^{-}\right]$yielding a $\mathrm{E}_{\mathrm{Cl}} \sim-69 \mathrm{mV}$. In some experiments, we applied the glutamate receptor antagonist DNQX at the end of the recording and we could not detect any residual response (not shown). $\mathrm{GABA}_{\mathrm{A}} \mathrm{R}$-mediated currents where pharmacologically isolated by applying $10 \mu \mathrm{M}$ of DNQX while recorded neurons at $-70 \mathrm{mV}$, using an intracellular solution with a $\left[\mathrm{Cl}^{-}\right]$yielding a calculated $\mathrm{E}_{\mathrm{Cl}}$ of $\sim-16 \mathrm{mV}$.

For paired recordings, unitary synaptic responses were elicited in voltage-clamp mode by brief somatic depolarizing steps evoking action currents in presynaptic cells. We used a high-chloride intracellular solution ( $\mathrm{E}_{\mathrm{Cl}}$ $\sim-16 \mathrm{mV}$ ), which allowed us measuring glutamatergic (PN-PV) and GABAergic synaptic responses (PV-PN, PVPV and autapses) simultaneously. Neurons were held at $-80 \mathrm{mV}$ and a train of 5 presynaptic spikes at $50 \mathrm{~Hz}$ was applied to infer short-term plasticity of synaptic responses.

Optical stimulation: $\mathrm{ChR} 2$ activation was obtained by brief $(0.3$ and $1.0 \mathrm{~ms})$ light flashes on cortical slices, using a blue LED ( $\lambda=470 \mathrm{~nm}$; Thorlab) collimated and coupled to the epifluorescence path of an Olympus BX51 microscope mounting a $60 \mathrm{X}$ water immersion objective (1.0 NA). Light intensity was controlled by the analog output of an A/D card (Digidata 1440A) via a power supply (Thorlabs, LEDD1), and calibrated with a photodiode and a power meter. Light power ranged between 0.053 and $1.12 \mathrm{~mW}$, over a spot of $0.28 \mathrm{~mm}$ of diameter. Although thalamocortical axons innervating cortical L4 were severed from their cell bodies, activation of ChR2expressing fibers generated robust responses onto postsynaptic neurons(Kloc and Maffei, 2014). Light-evoked responses were recorded in voltage clamp mode in L4 PV cells and PNs. Direct recruitment of cortical neurons was examined in ACSF containing $1 \mu \mathrm{M}$ of TTX, to remove polysynaptic activity, and $100 \mu \mathrm{M}$ of the $\mathrm{K}^{+}$-channel antagonist 4-aminopyridine (4-AP), to enhance axonal depolarization. This approach ensures monosynaptic transmission from thalamocortical afferents selectively, without contamination of polysynaptic activity(Petreanu et al., 2009). Disynaptic inhibition was measured in regular ACSF and IPSCs were isolated by holding neurons at the reversal potential for glutamate-mediated responses (between +10 and $+15 \mathrm{mV}$, taking into account the liquid junction potential and series resistance). 
In order to minimize response variability due to potential different level of expression of ChR2 across animals and slices, we performed optical stimulations at a light intensity inducing detectable responses with occasional failures. This light intensity was refereed as threshold stimulation(Gabernet et al., 2005;Bagnall et al., 2011). The duration of light stimulations were $0.3 \mathrm{~ms}$ for feed-forward (FFI), and $1 \mathrm{~ms}$ for thalamocortical glutamatergic activation. The stimulus duration was longer in the latter case, due to the presence of TTX and 4-AP. With these constant pulse durations and by varying illumination intensity, the threshold stimulation was determined for each cell.

For all experiments, neurons were discarded from the analysis if the access resistance was $>30 \mathrm{M} \Omega$. All drugs were obtained from Tocris Cookson (Bristol, UK) or Sigma-Aldrich (St-Louis, USA).

\section{Immunohistochemistry}

Thick slices used for electrophysiology experiments $(350 \mu \mathrm{m})$ were fixed overnight in $4 \%$ paraformaldehyde in phosphate buffer $(\mathrm{PB}, \mathrm{pH} 7.4)$ at $4^{\circ} \mathrm{C}$. Slices were then rinsed three times at room temperature (10 min each time) in PBS and pre-incubated $1 \mathrm{~h}$ at room temperature in a blocking solution of PBS with $0.3 \%$ Triton and $10 \%$ bovine serum albumin. Slices were then incubated 3.5 hours at room temperature in PBS with $0.3 \%$ Triton and Fluorescein Wisteria floribunda lectin (WFA-FITC; Vector Laboratories) which binds to the $\mathrm{N}$ acetylgalactosamime of PNNs. Slices were then rinsed three times in PBS (10 min each) at room temperature, coverslipped in mounting medium and stored at $4{ }^{\circ} \mathrm{C}$. Immunofluorescence was then observed with an epifluorescence macroscope (Nikon AZ100) and images were acquired. This post-hoc staining was used to check PNN degradation. Experiments were discarded if a clear disruption of the extracellular matrix was not evident. Parvalbumin staining was realized on $40 \mu \mathrm{m}$-thick slices. Slices were fixed overnight in $4 \%$ paraformaldehyde in phosphate buffer ( $\mathrm{PB}, \mathrm{pH} 7.4)$ at $4^{\circ} \mathrm{C}$ and rinsed (10 min each time) in PBS. A pre-incubation in a blocking solution of PBT with $0.2 \%$ Triton and 3\% bovine serum albumin was done at room temperature for $1 \mathrm{~h}$. Slices were incubated overnight $\left(4^{\circ} \mathrm{C}\right)$ in the same blocking solution containing the primary rabbit ant-PV antibody (1:1000; Thermo Scientific). Slices were then rinsed three times in PBS (10 min each) at room temperature and incubated with Cy-2-anti-rabbit antibody (1:400; Jackson IR) for 3.5 hours at room temperature. Slices were then rinsed three times in PBS (10 min each) at room temperature and coverslipped in mounting medium. Immunofluorescence was then observed with a confocal microscope (Olympus, FV-1000) or a slide scanner (Zeiss, Axio Scan.Z1) and images were acquired.

\section{Data analysis}

Experiments on firing dynamics and unitary paired recordings were analyzed with Clampfit (Molecular Devices), Origin (Microcal) and custom-made scripts in Matlab (the Mathworks). Firing frequencies were averaged across three trials. Failures of unitary synaptic responses were included in the analysis.

Spontaneous and miniatures synaptic events were detected using custom written software (Wdetecta, courtesy J. R. Huguenard, Stanford University) based on an algorithm that calculate the derivative of the current trace to find events that cross a certain defined threshold. Amplitude and frequencies of the events were then binned and sorted, using other custom-written routines (courtesy J. R. Huguenard, Stanford University) (Ulrich and Huguenard, 1996; Manseau et al., 2010). 
663 AP waveforms were investigated using a phase plot analysis based on a routine developed with Matlab (courtesy

664 J. Simonnet) to measure AP threshold, peak and width. Passive properties as well as optical stimulation experiments were analyzed with Clampfit. Light-induced EPSCs were averaged across at least 20 trials and

666 failures were removed from the analysis (threshold stimulation).

667 The in vivo recordings were analyzed by a custom program written in Matlab. Data were acquired as a long 668 continuous session together with a synch signal generated by the visual stimulator. Average VEPs were obtained 669 by phase locking the trial averaging on the synch signal. Spectral analysis was performed within the same software package using the Chronux toolbox for multitaper spectral analysis.

671

\section{$672 \quad$ Statistical tests}

673 All statistical analysis were performed in Prism (GraphPad Software, Inc.). Normality of the data was systematically assessed (D'Agostino \& Pearson omnibus normality test). Normal distributions were statistically compared using paired $t$ test two-tailed or One-way ANOVA followed by Bonferroni's Multiple Comparison post hoc test for more than two independent groups. When data distributions were not normal or $n$ was small, nonparametric tests were performed (Mann Whitney test and Kruskal-Wallis test followed by Dunn's multiple comparison test for more than two groups, respectively). For the comparison of firing dynamics and short-term plasticity, Two-way repeated-measures ANOVAs were used followed by post-hoc Holm Sidak and Bonferroni's multiple comparison tests for in vivo and in vitro experiments, respectively. Differences were considered significant if $\mathrm{p}<0.05(* \mathrm{p}<0.05, * * \mathrm{p}<0.01, * * * \mathrm{p}<0.001, * * * * \mathrm{p}<0.0001)$. Values are presented as mean \pm SEM of $n$ experiments.

683 To measure if MD effectively changed ChABC-mediated effects on synaptic transmission, we used a variation of Cohen's d(Cohen, 1988;Lakens, 2013), Glass' $\Delta$, which uses only the standard deviation of the control group(Glass et al., 1981;Lakens, 2013), when each group has a different standard deviation.

$$
\text { Glass' } \Delta=\left(\mathrm{M}_{2}-\mathrm{M}_{1}\right) / \mathrm{SD}_{1}
$$

Where $\mathrm{M}_{1}$ and $\mathrm{M}_{2}$ are the mean values for control and $\mathrm{MD}$ animals, and $\mathrm{SD}_{1}$ is the standard deviation of the control animals.

689

\section{Data and code availability}

691 The data and code that support the findings of this study are available from the corresponding authors upon 692 reasonable request. 
Supplemental Material for:

\section{Perineuronal nets set the strength of thalamic recruitment of interneurons in the adult visual cortex}

Giulia Faini ${ }^{1}$, Andrea Aguirre ${ }^{1}$, Silvia Landi ${ }^{2}$, Tommaso Pizzorusso ${ }^{3,4}$, Gian Michele Ratto ${ }^{2}$, Charlotte Deleuze ${ }^{1}$, Alberto Bacci ${ }^{1}$

Correspondence to: alberto.bacci@icm-institute.org 
Figure S1. PNNs surrounding PV cells are abundant in L4 of V1.
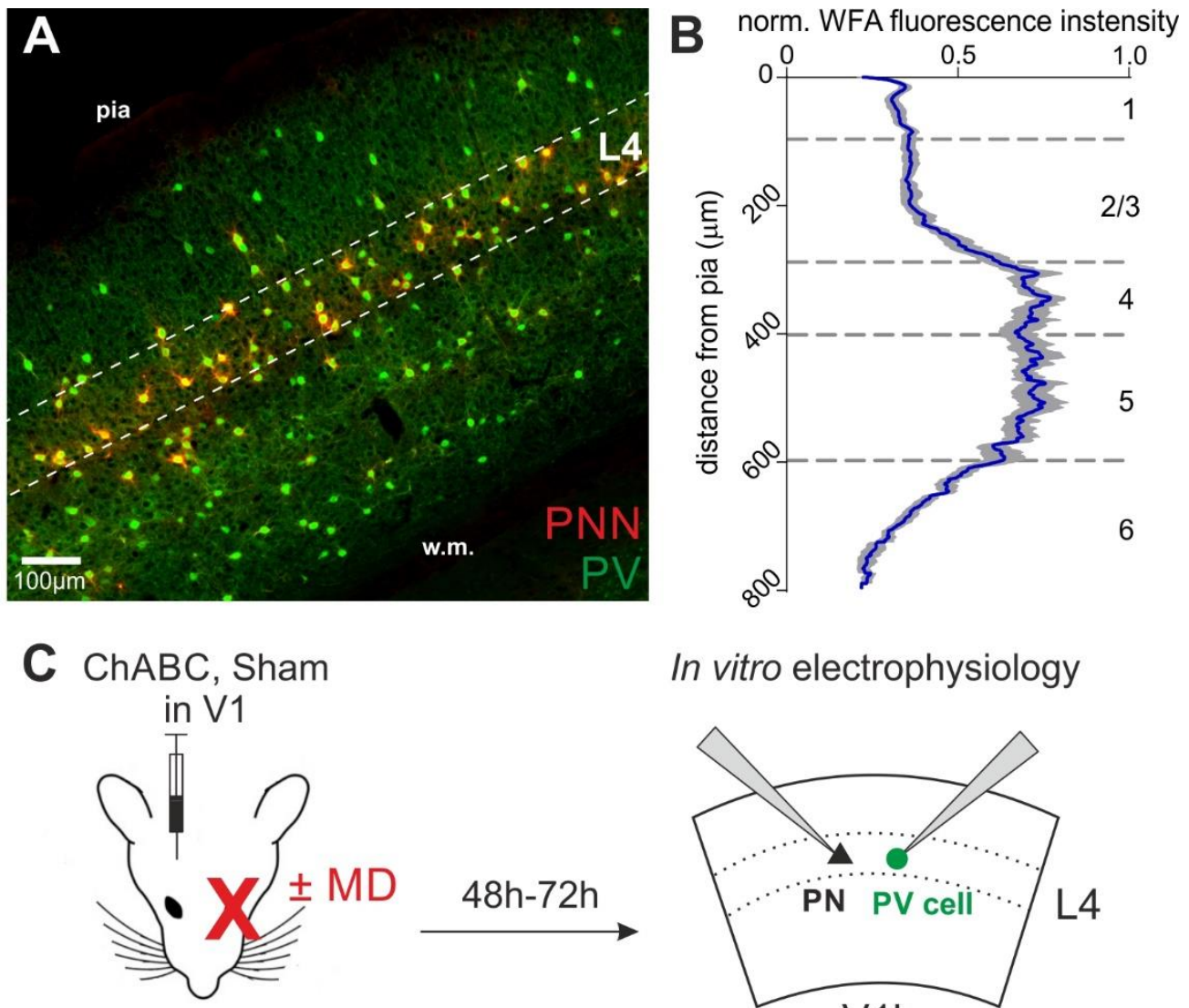

In vitro electrophysiology

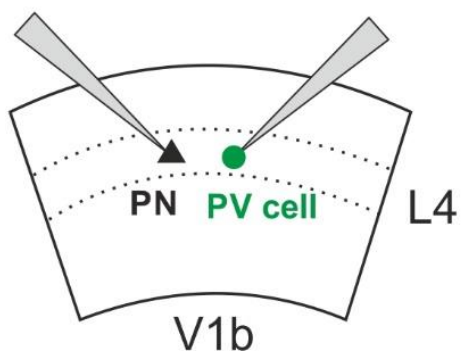

A, Epifluorescence image of primary visual cortex (coronal slice, 200 $\mu \mathrm{m}$ ) from an adult mouse. PNNs are in red (WFA staining) and PV cells in green (parvalbumin staining). Dotted lines delimitate layer 4. B, Normalized WFA fluorescence intensity (X axis) across cortical layers ( $\mathrm{Y}$ axis). Blue line: mean; grey area: standard deviation $(\mathrm{n}=10$ slices from 7 mice). $\mathbf{C}$, Experimental protocol: mice were injected in $\mathrm{V} 1$ in vivo with ChABC (or PBS, in sham-treated animals). After 2-3 days, we obtained acute cortical slices and recorded PV cells or PNs in layer 4 of the binocular portion of V1 (V1b). Some mice underwent monocular deprivation. $\mathrm{PV}=$ parvalbumin-positive interneuron. $\mathrm{PN}=$ principal neuron. $\mathrm{MD}=$ monocular deprivation. 
Figure S2. Firing dynamics and passive properties are not altered by PNN removal in adult animals.
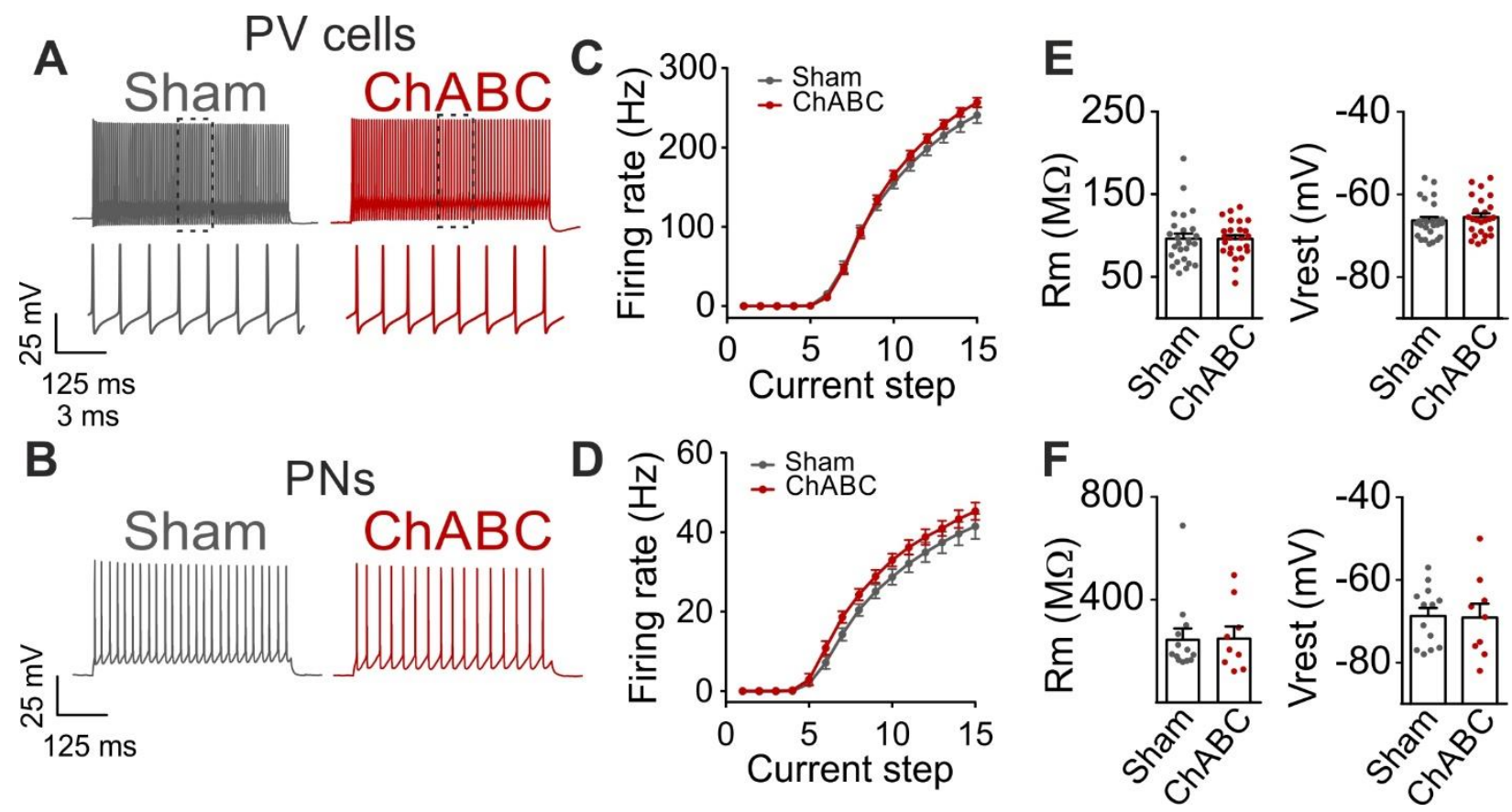

A, Characteristic firing pattern of PV cells in response to depolarizing current injections, in control condition (Sham, grey) and in PNN-depleted animals (ChABC, red). Insets illustrate firing at an expanded timescale corresponding to the dotted region in the upper part. $\mathbf{B}$, Example firing of PNs in presence (Sham, grey) and absence (ChABC, red) of PNNs. C-D, Average frequency-current $(f-i)$ curves of PV cells $(C)$ and PNs (d). E-F, Passive properties of PV cells (E) and PNs (F). PV=parvalbumin-positive interneuron. $\mathrm{PN}=$ principal neuron. All values are in Table $\mathrm{S} 1$. 
Figure S3. Monocular deprivation does not affect firing dynamics and passive properties following PNN removal in adult animals.

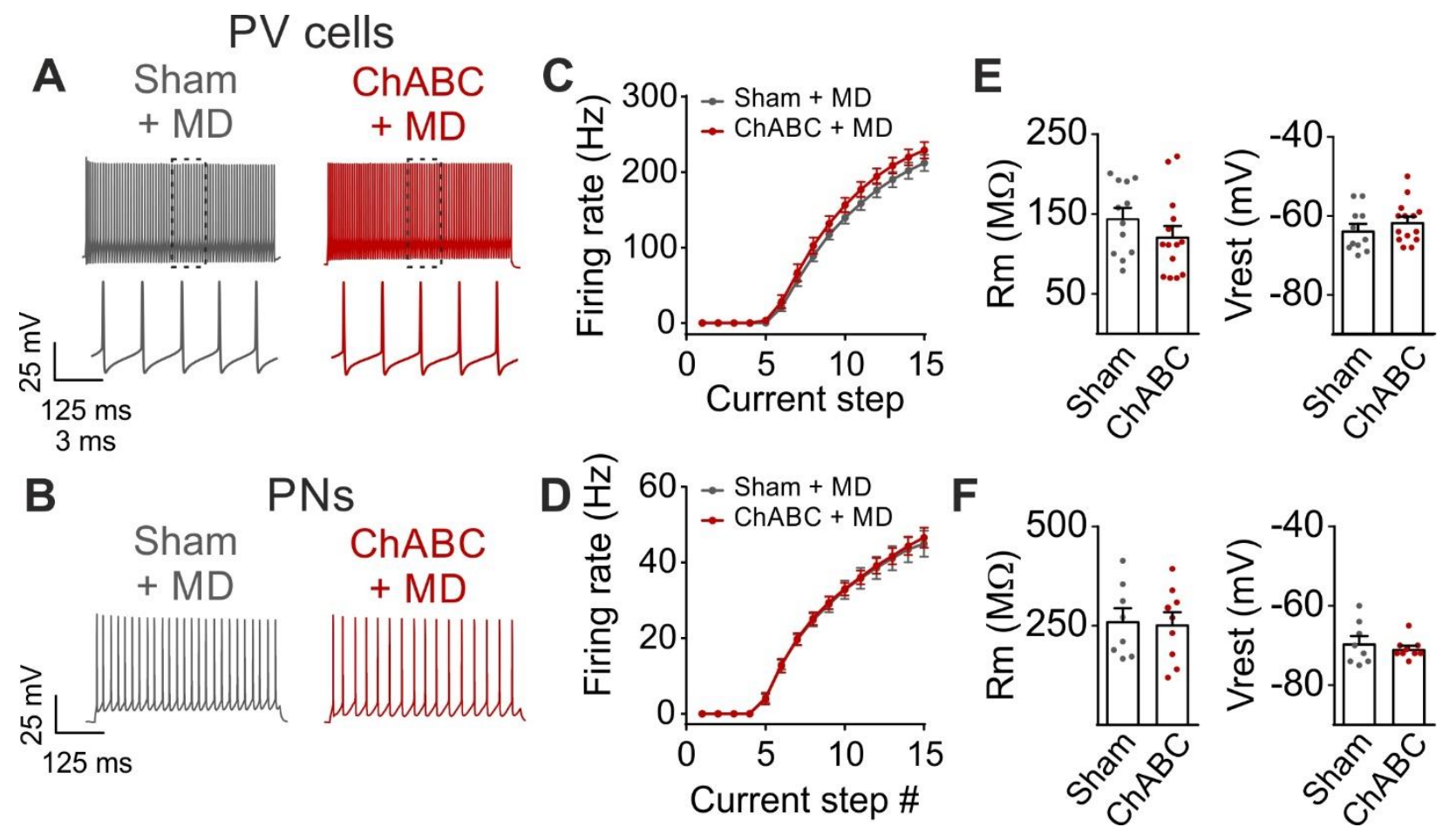

A-B, Characteristic firing of PV cells and PNs respectively, in response to depolarizing current injections, in control condition (Sham, grey) and in ChABC-treated animals (ChABC, red). Inset in a shows the firing behavior of PV cells at an expanded time scale. C-D, Average $f-i$ curves of PV cells (C) and PNs (D). E-F, Passive properties of PV cells (E) and PNs (F). $\mathrm{PV}=$ parvalbumin-positive interneuron. $\mathrm{PN}=$ principal neuron. $\mathrm{MD}=$ monocular deprivation. All experiments were performed in sensory deprived animals (MD). All values are in Table S1. 
Figure S4. Glutamatergic and GABAergic synaptic transmission onto PNs are unaffected by PNN degradation.

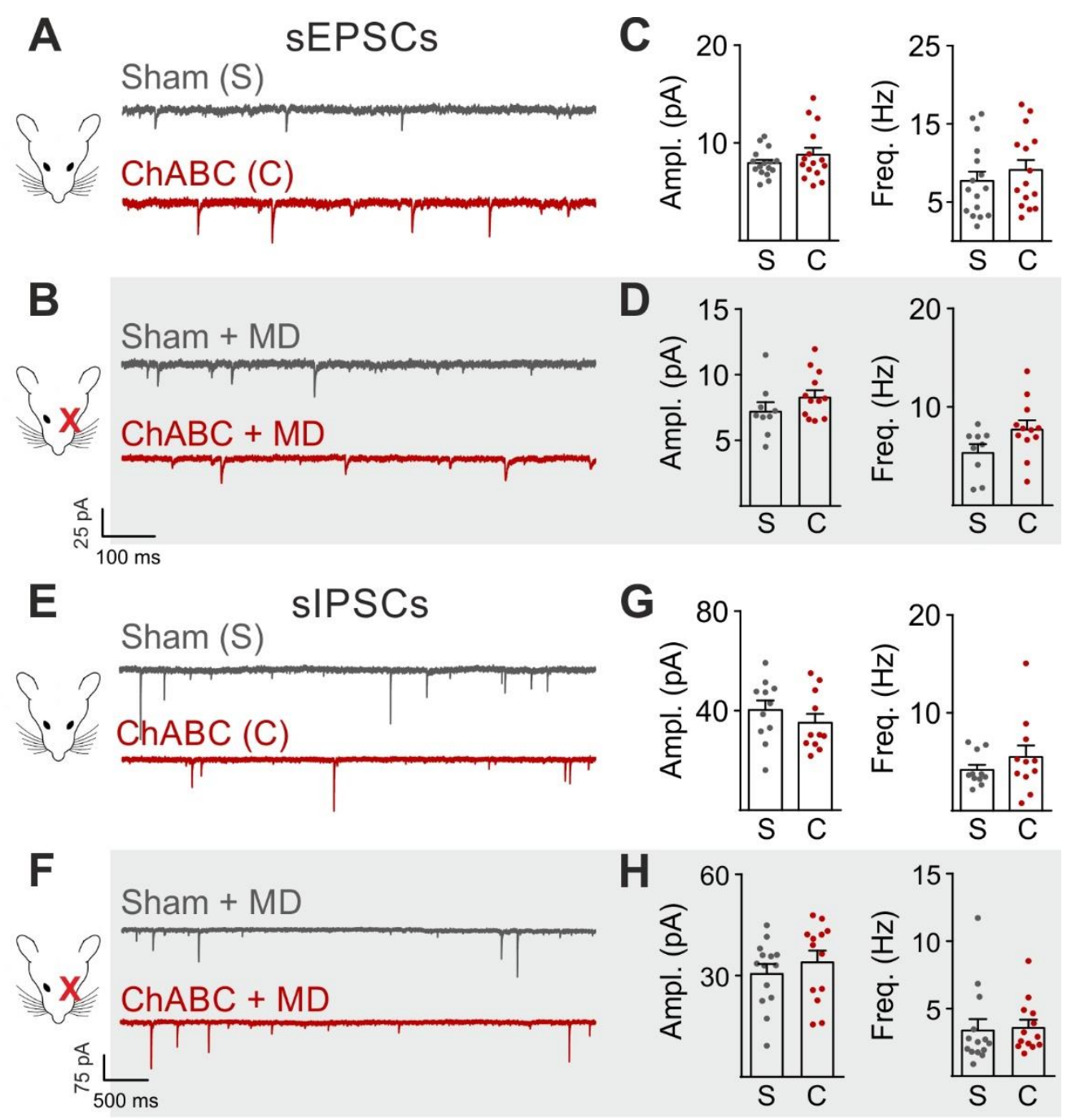

A-B, Example voltage-clamp traces of sEPSCs recorded in absence (A) and presence (B) of MD, in control animals (Sham, grey) and after ChABC treatment (ChABC, red). C-D, Plots of average sEPSC amplitude (left) and frequency (right), in absence of MD (c) and in monoculardeprived animals (D), in control animals (S, grey) and after PNN removal (C, red). E-H, Same as in (A-D), but for sIPSCs, pharmacologically isolated in presence of the glutamate receptor antagonist DNQX. All values are in Supplementary Tables 3 and 5. 
Figure S5. Probability of L4 connected pairs in young and adult mouse V1.

\section{Probability of connected pairs}

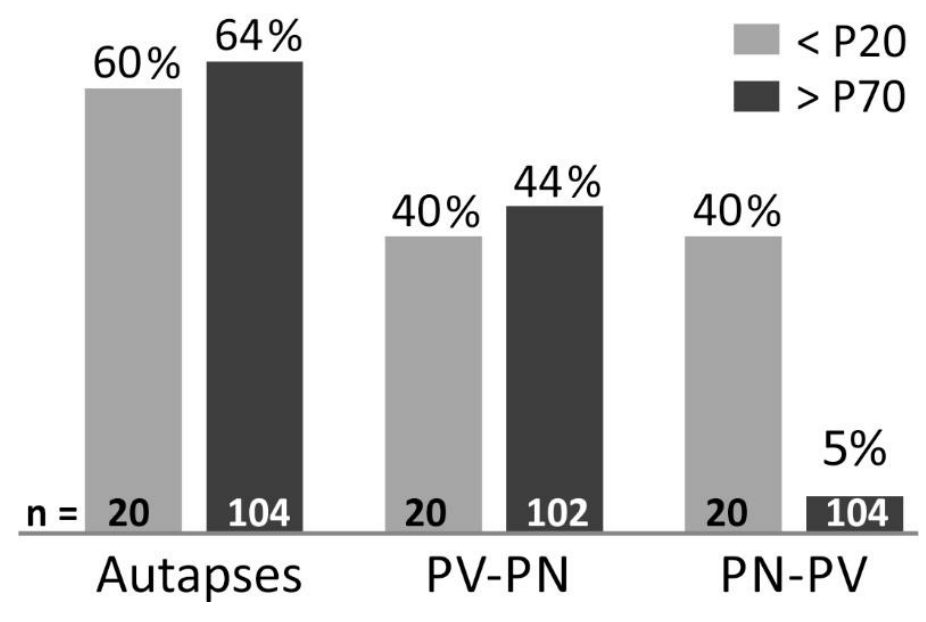

Incidence of autaptic neurotransmission are shown in the left part, PV-PN and PN-PV connectivity in the middle and right part, respectively. Grey bars: <P20 mice; Black bars: >P70 mice. Note that glutamatergic synapses onto PV cells are very rare in adult animals (>P70). $\mathrm{n}=$ number of tested pairs. PV: parvalbumin-positive interneuron. PN: principal neuron. 
Figure S6. In vivo expression of the light-sensitive opsin ChR2 in the dLGN to measure the strength of thalamocortical connections impinging L4 neurons.
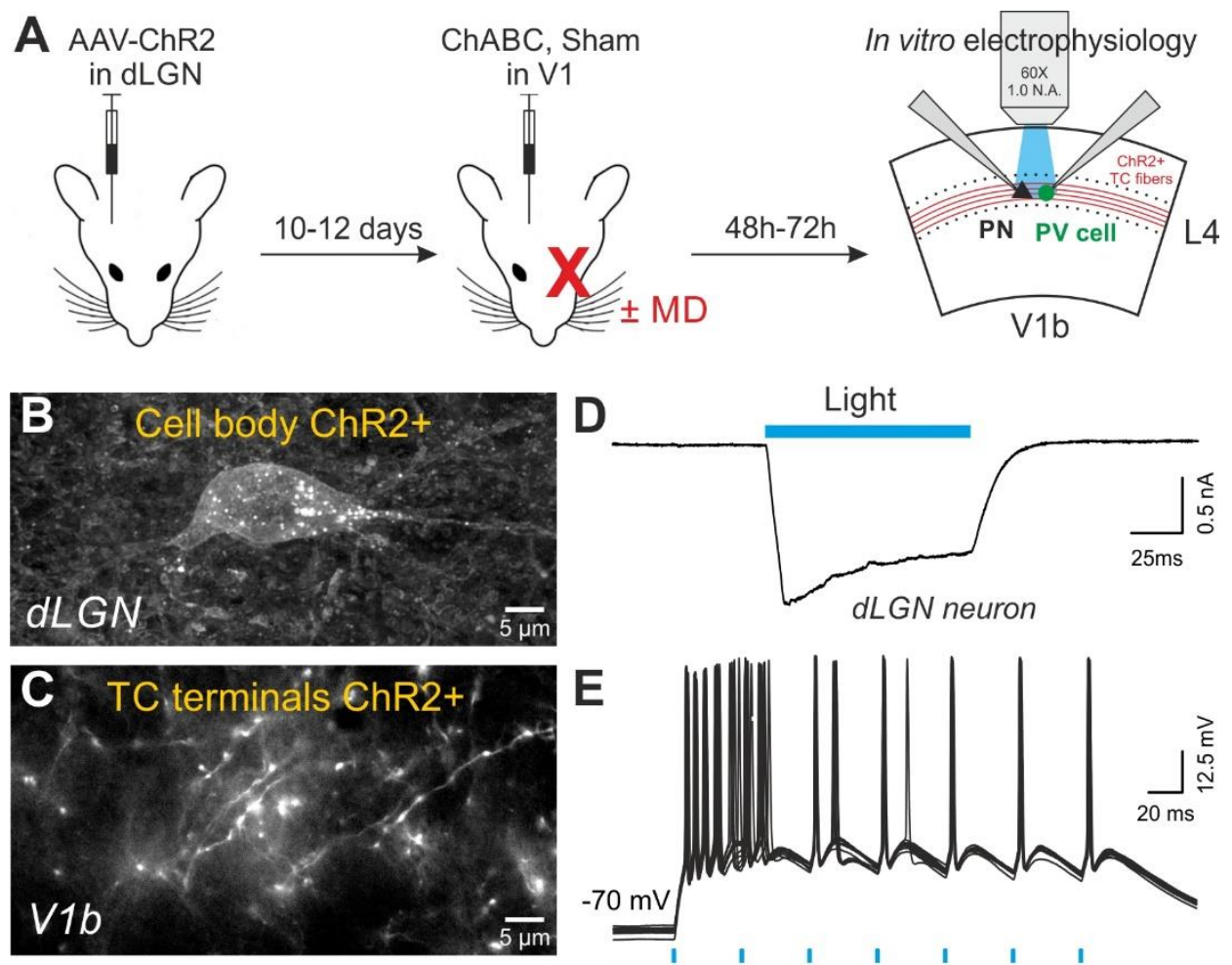

A, Protocol of dual surgery. CamKII-AAV-ChR2-mCherry was expressed in dLGN of adult mice. 10-12 days later, the same mouse was subject to a second stereotaxic injection of ChABC (or PBS) in order to disrupt PNNs in V1. In addition, some mice underwent a monocular deprivation. In vitro optical stimulation was performed by shining light in V1b, 2-3 days postChABC injections. B, Confocal image of a mCherry (ChR2)-positive glutamatergic cell in dLGN. C, Confocal image of mCherry (ChR2)-positive fibers in V1b. D, Example of a typical photo-activated current, recorded in voltage clamp in a dLGN ChR2-positive neuron, following blue light illumination. E, Representative current-clamp traces of a ChR2-positive dLGN neuron showing reliable action potential firing (20 traces overlapped) in response to brief light flashes. Note the typical burst firing of thalamic neuron in response to the first flash. Blue bars indicate photo-stimulations (blue light, $470 \mathrm{~nm}$ ). 
Table S1: Passive properties of PV cells and PNs following PNN removal and monocular deprivation.

\begin{tabular}{|c|c|c|c|c|c|}
\hline PV cells & $\mathrm{n}$ & $\mathrm{N}$ & $\begin{array}{c}\text { First injected } \\
\text { current* }(\mathrm{pA})\end{array}$ & $\mathrm{Rm}(\mathrm{M} \Omega)$ & Vrest $(\mathrm{mV})$ \\
\hline Sham & 26 & 12 & $-115.27 \pm 6.57$ & $96.2 \pm 6.2$ & $-66.31 \pm 0.87$ \\
\hline ChABC & 25 & 9 & $-104.68 \pm 4.98$ & $96.02 \pm 4.5$ & $-65.47 \pm 0.92$ \\
\hline Sham + MD & 10 & 5 & $-75.40 \pm 6.65$ & $144.7 \pm 13$ & $-63.67 \pm 1.7$ \\
\hline ChABC + MD & 13 & 8 & $-88.23 \pm 7.99$ & $121.6 \pm 13$ & $-61.57 \pm 1.4$ \\
\hline
\end{tabular}

\begin{tabular}{|c|c|c|c|c|c|}
\hline PNs & $\mathrm{n}$ & $\mathrm{N}$ & $\begin{array}{c}\text { First injected } \\
\text { current* }(\mathrm{pA})\end{array}$ & $\mathrm{Rm}(\mathrm{M} \Omega)$ & Vrest $(\mathrm{mV})$ \\
\hline Sham & 26 & 12 & $-50.57 \pm 3.04$ & $248.7 \pm 39.9$ & $-68.73 \pm 1.98$ \\
\hline ChABC & 25 & 9 & $-49.56 \pm 6.64$ & $252.5 \pm 44.1$ & $-69.04 \pm 3.3$ \\
\hline Sham + MD & 10 & 5 & $-47.42 \pm 6.24$ & $261.4 \pm 33$ & $-69.5 \pm 1.9$ \\
\hline ChABC + MD & 13 & 8 & $-48.33 \pm 6.04$ & $253 \pm 31$ & $-70.89 \pm 0.85$ \\
\hline
\end{tabular}

Mean values \pm SEM. $\mathrm{n}=$ number of cells; $\mathrm{N}=$ number of mice.

*First injected current to induce a $\Delta \mathrm{V}$ of $-10 \mathrm{mV}$; incremental current steps in $f$-i plots were half this value.

Table S2: Action potential parameters of PV cells and PNs following PNN removal and monocular deprivation.

\begin{tabular}{|c|c|c|c|c|c|}
\hline PV cells & $\mathrm{n}$ & $\mathrm{N}$ & AP threshold $(\mathrm{mV})$ & AP width $(\mathrm{ms})$ & AP peak $(\mathrm{mV})$ \\
\hline Sham & 12 & 7 & $-48.95 \pm 1.10$ & $0.32 \pm 0.02$ & $20.84 \pm 1.5$ \\
\hline ChABC & 10 & 5 & $-50.45 \pm 0.75$ & $0.31 \pm 0.017$ & $23.04 \pm 1.6$ \\
\hline Sham + MD & 8 & 6 & $-51.92 \pm 0.92$ & $0.39 \pm 0.015$ & $17.59 \pm 1.8$ \\
\hline ChABC + MD & 10 & 6 & $-51.71 \pm 0.89$ & $0.38 \pm 0.014$ & $18.58 \pm 1.4$ \\
\hline
\end{tabular}

\begin{tabular}{|c|c|c|c|c|c|}
\hline PNs & $\mathrm{n}$ & $\mathrm{N}$ & AP threshold $(\mathrm{mV})$ & AP width $(\mathrm{ms})$ & AP peak $(\mathrm{mV})$ \\
\hline Sham & 12 & 9 & $-47.98 \pm 1.4$ & $0.87 \pm 0.07$ & $29.49 \pm 3.2$ \\
\hline ChABC & 9 & 4 & $-49.18 \pm 1.8$ & $0.95 \pm 0.03$ & $28.40 \pm 3.3$ \\
\hline Sham + MD & 8 & 5 & $-50.56 \pm 1.3$ & $1.11 \pm 0.08$ & $28.66 \pm 3.1$ \\
\hline ChABC + MD & 9 & 5 & $-49.97 \pm 1.3$ & $1.03 \pm 0.03$ & $23.18 \pm 2.3$ \\
\hline
\end{tabular}

Mean values \pm SEM. $\mathrm{n}=$ number of cells; $\mathrm{N}=$ number of mice. 
Table S3: Glutamatergic neurotransmission onto PV cells and PNs following PNN degradation and monocular deprivation.

\begin{tabular}{|c|c|c|c|c|}
\hline PV cells & $\mathrm{n}$ & $\mathrm{N}$ & sEPSC ampl. $(\mathrm{pA})$ & sEPSC freq. $(\mathrm{Hz})$ \\
\hline Sham & 29 & 14 & $9.81 \pm 0.4$ & $33.50 \pm 3.0$ \\
\hline ChABC & 24 & 9 & $11.88 \pm 0.5$ & $46.80 \pm 4.7$ \\
\hline Sham + MD & 14 & 6 & $9.52 \pm 0.7$ & $20.15 \pm 2.5$ \\
\hline ChABC + MD & 23 & 9 & $9.46 \pm 0.2$ & $34.47 \pm 2.2$ \\
\hline
\end{tabular}

\begin{tabular}{|c|c|c|c|c|}
\hline PNs & $\mathrm{n}$ & $\mathrm{N}$ & sEPSC ampl. $(\mathrm{pA})$ & sEPSC freq. $(\mathrm{Hz})$ \\
\hline Sham & 16 & 12 & $7.94 \pm 0.4$ & $7.70 \pm 1.2$ \\
\hline ChABC & 15 & 9 & $8.80 \pm 0.7$ & $9.11 \pm 1.3$ \\
\hline Sham + MD & 9 & 5 & $7.25 \pm 0.7$ & $5.43 \pm 0.8$ \\
\hline ChABC + MD & 12 & 8 & $8.47 \pm 0.5$ & $7.80 \pm 0.8$ \\
\hline
\end{tabular}

\begin{tabular}{|c|c|c|c|c|}
\hline PV cells & $\mathrm{n}$ & $\mathrm{N}$ & mEPSC ampl. (pA) & msEPSC freq. (Hz) \\
\hline Sham & 15 & 7 & $7.98 \pm 0.4$ & $27.30 \pm 2.5$ \\
\hline ChABC & 13 & 8 & $7.65 \pm 0.3$ & $40.76 \pm 2.9$ \\
\hline Sham + MD & 10 & 5 & $8.64 \pm 0.4$ & $22.34 \pm 3.4$ \\
\hline ChABC + MD & 10 & 5 & $8.18 \pm 0.4$ & $22.43 \pm 1.3$ \\
\hline
\end{tabular}

sEPSC: spontaneous excitatory postsynaptic currents. mEPSC: miniature excitatory postsynaptic currents recorded in TTX. Mean values \pm SEM. $n=$ number of cells, $N=$ number of mice.

Table S4: Thalamocortical glutamatergic responses on PV cells and PNs, in control conditions and after PNN removal and monocular deprivation.

\begin{tabular}{|c|c|c|c|c|c|}
\hline PV cells & $\mathrm{n}$ & $\mathrm{N}$ & Area $\left(\mathrm{pA}^{*} \mathrm{~ms}\right)$ & Light power $(\mathrm{mW})$ & Fail. rate \\
\hline Sham & 18 & 8 & $156 \pm 22.7$ & $0.26 \pm 0.07$ & $0.15 \pm 0.09$ \\
\hline ChABC & 16 & 7 & $358.9 \pm 85.5$ & $0.14 \pm 0.02$ & $0.17 \pm 0.04$ \\
\hline Sham $+\mathrm{MD}$ & 8 & 3 & $91.24 \pm 15.0$ & $0.18 \pm 0.03$ & $0.44 \pm 0.03$ \\
\hline ChABC $+\mathrm{MD}$ & 8 & 3 & $169.7 \pm 14.8$ & $0.17 \pm 0.03$ & $0.49 \pm 0.08$ \\
\hline
\end{tabular}

\begin{tabular}{|c|c|c|c|c|c|}
\hline PNs & $\mathrm{n}$ & $\mathrm{N}$ & Area $\left(\mathrm{pA} *^{*} \mathrm{~ms}\right)$ & Light power $(\mathrm{mW})$ & Fail. rate \\
\hline Sham & 8 & 4 & $146.1 \pm 19.0$ & $0.13 \pm 0.02$ & $0.35 \pm 0.06$ \\
\hline ChABC & 8 & 3 & $162.7 \pm 22.4$ & $0.14 \pm 0.01$ & $0.41 \pm 0.07$ \\
\hline Sham + MD & 8 & 4 & $95.85 \pm 9.4$ & $0.17 \pm 0.03$ & $0.36 \pm 0.05$ \\
\hline ChABC + MD & 7 & 3 & $131.1 \pm 27.4$ & $0.18 \pm 0.03$ & $0.28 \pm 0.07$ \\
\hline
\end{tabular}

Mean values \pm SEM. $\mathrm{n}=$ number of cells, $\mathrm{N}=$ number of mice. Responses were measured at threshold in presence of TTX and 4-AP.

Table S5: GABAergic neurotransmission onto PV cells and PNs following PNN degradation and MD. 


\begin{tabular}{|c|c|c|c|c|}
\hline PV cells & $\mathrm{n}$ & $\mathrm{N}$ & sIPSC ampl. $(\mathrm{pA})$ & sIPSC freq. $(\mathrm{Hz})$ \\
\hline Sham & 16 & 7 & $25.37 \pm 2.0$ & $7.59 \pm 1.0$ \\
\hline ChABC & 17 & 7 & $37.60 \pm 4.5$ & $11.88 \pm 1.7$ \\
\hline Sham + MD & 15 & 5 & $32.04 \pm 2.6$ & $4.44 \pm 0.6$ \\
\hline ChABC + MD & 14 & 5 & $34.21 \pm 3.4$ & $7.03 \pm 0.9$ \\
\hline
\end{tabular}

\begin{tabular}{|c|c|c|c|c|}
\hline PNs & $\mathrm{n}$ & $\mathrm{N}$ & sIPSC ampl. $(\mathrm{pA})$ & sIPSC freq. $(\mathrm{Hz})$ \\
\hline Sham & 11 & 6 & $40.33 \pm 3.4$ & $4.18 \pm 0.51$ \\
\hline ChABC & 11 & 8 & $35.15 \pm 3.6$ & $5.49 \pm 1.2$ \\
\hline Sham + MD & 14 & 4 & $30.83 \pm 2.6$ & $3.46 \pm 0.8$ \\
\hline ChABC + MD & 13 & 4 & $34.22 \pm 3.2$ & $3.65 \pm 0.5$ \\
\hline
\end{tabular}

\begin{tabular}{|c|c|c|c|c|}
\hline PV cells & $\mathrm{n}$ & $\mathrm{N}$ & mIPSC ampl. $(\mathrm{pA})$ & mIPSC freq. $(\mathrm{Hz})$ \\
\hline Sham & 12 & 5 & $35.13 \pm 4.1$ & $4.62 \pm 0.6$ \\
\hline ChABC & 10 & 6 & $30.44 \pm 3.6$ & $5.14 \pm 0.7$ \\
\hline Sham + MD & 10 & 3 & $35.88 \pm 2.9$ & $4.19 \pm 0.4$ \\
\hline ChABC + MD & 8 & 3 & $35.81 \pm 3.2$ & $6.92 \pm 1.4$ \\
\hline
\end{tabular}

sIPSCs: spontaneous inhibitory postsynaptic currents. mIPSCs: miniature inhibitory postsynaptic currents recorded in TTX. Mean values \pm SEM. $n=$ number of cells, $N=$ number of mice.

Table S6: Unitary GABAergic connections from PV cells, in control conditions and after PNN removal and monocular deprivation.

\begin{tabular}{|c|c|c|c|}
\hline PV-PV syn + aut & $\mathrm{n}$ & $\mathrm{N}$ & Conductance $(\mathrm{nS})$ \\
\hline Sham & 33 & 10 & $5.146 \pm 0.82$ \\
\hline ChABC & 26 & 11 & $5.550 \pm 0.88$ \\
\hline Sham + MD & 11 & 4 & $3.268 \pm 0.52$ \\
\hline ChABC + MD & 8 & 4 & $6.103 \pm 1.61$ \\
\hline
\end{tabular}

\begin{tabular}{|c|c|c|c|}
\hline PV-PN & $\mathrm{n}$ & $\mathrm{N}$ & Conductance $(\mathrm{nS})$ \\
\hline Sham & 10 & 6 & $2.527 \pm 0.7$ \\
\hline ChABC & 13 & 7 & $3.374 \pm 0.9$ \\
\hline Sham + MD & 8 & 3 & $3.945 \pm 1.3$ \\
\hline ChABC + MD & 9 & 5 & $5.672 \pm 1.4$ \\
\hline
\end{tabular}

Mean values \pm SEM. $\mathrm{n}=$ number of cells, $\mathrm{N}=$ number of mice. 
Table S7: Thalamocortical feed-forward inhibition on PV cells and PNs after PNN removal and monocular deprivation.

\begin{tabular}{|c|c|c|c|c|c|c|c|}
\hline PV cells & $\mathrm{n}$ & $\mathrm{N}$ & Stim. & $\begin{array}{c}\text { Amplitude } \\
(\mathrm{pA})\end{array}$ & $\begin{array}{c}\text { Light power } \\
(\mathrm{mW})\end{array}$ & $\begin{array}{c}\text { Latency } \\
(\mathrm{ms})\end{array}$ & Fail. rate \\
\hline Sham & 10 & 7 & thresh & $208.4 \pm 40.7$ & $0.35 \pm 0.05$ & $7.13 \pm 0.35$ & $0.25 \pm 0.03$ \\
\hline ChABC & 9 & 7 & thresh & $1095 \pm 209$ & $0.33 \pm 0.06$ & $6.09 \pm 0.43$ & $0.28 \pm 0.07$ \\
\hline Sham $+\mathrm{MD}$ & 10 & 4 & thresh & $257.5 \pm 41.2$ & $0.34 \pm 0.05$ & $5.98 \pm 0.26$ & $0.37 \pm 0.05$ \\
\hline ChABC $+\mathrm{MD}$ & 10 & 5 & thresh & $557.1 \pm 122$ & $0.30 \pm 0.06$ & $6.03 \pm 0.19$ & $0.33 \pm 0.07$ \\
\hline
\end{tabular}

\begin{tabular}{|c|c|c|c|c|c|c|c|}
\hline PNs & $\mathrm{n}$ & $\mathrm{N}$ & Stim. & $\begin{array}{c}\text { Amplitude } \\
(\mathrm{pA})\end{array}$ & $\begin{array}{c}\text { Light power } \\
(\mathrm{mW})\end{array}$ & $\begin{array}{c}\text { Latency } \\
(\mathrm{ms})\end{array}$ & Fail. rate \\
\hline Sham & 14 & 7 & thresh & $162.1 \pm 19.32$ & $0.35 \pm 0.04$ & $6.81 \pm 0.29$ & $0.42 \pm 0.05$ \\
\hline ChABC & 16 & 6 & thresh & $195.2 \pm 35.79$ & $0.36 \pm 0.05$ & $6.59 \pm 0.36$ & $0.36 \pm 0.05$ \\
\hline Sham + MD & 15 & 6 & thresh & $238.2 \pm 32.12$ & $0.33 \pm 0.03$ & $6.11 \pm 0.15$ & $0.39 \pm 0.03$ \\
\hline ChABC + MD & 14 & 5 & thresh & $404 \pm 75.96$ & $0.24 \pm 0.03$ & $6.17 \pm 0.16$ & $0.32 \pm 0.03$ \\
\hline Sham & 7 & 2 & $\mathrm{x} 1.5$ & $860.4 \pm 156$ & $0.35 \pm 0.04$ & $5.2 \pm 0.21$ & $/$ \\
\hline ChABC & 7 & 2 & $\times 1.5$ & $1715 \pm 255$ & $0.28 \pm 0.02$ & $5.1 \pm 0.16$ & $/$ \\
\hline Sham + MD & 11 & 4 & $\times 1.5$ & $1081 \pm 172$ & $0.39 \pm 0.04$ & $5.1 \pm 0.09$ & $/$ \\
\hline ChABC + MD & 11 & 4 & $\mathrm{x} 1.5$ & $1257 \pm 199$ & $0.39 \pm 0.04$ & $5.2 \pm 0.11$ & $/$ \\
\hline
\end{tabular}

Mean values \pm SEM. $\mathrm{n}=$ number of cells, $\mathrm{N}=$ number of mice. Responses were measured at threshold stimulation (thresh.) or at $1.5 \mathrm{x}$ thresh. (x1.5). 
Table S8: Glutamatergic and GABAergic neurotransmission onto PV cells and PNs during development.

\begin{tabular}{|c|c|c|c|c|}
\hline PV cells & $\mathrm{n}$ & $\mathrm{N}$ & sEPSC ampl. (pA) & sEPSC freq. (Hz) \\
\hline$<$ P20 & 16 & 9 & $15.79 \pm 0.5$ & $27.85 \pm 1.6$ \\
\hline P25-P32 & 18 & 7 & $13.53 \pm 0.4$ & $37.40 \pm 3.9$ \\
\hline P40-P60 & 22 & 11 & $11.47 \pm 0.6$ & $36.73 \pm 3.4$ \\
\hline$>$ P70 & 27 & 9 & $11.27 \pm 0.41$ & $25.40 \pm 1.9$ \\
\hline \multicolumn{2}{|l}{} & sIPSC ampl. (pA) & sIPSC freq. (Hz) \\
\hline <P20 & 12 & 5 & $32.24 \pm 3.2$ & $7.29 \pm 1.7$ \\
\hline P25-P32 & 9 & 4 & $26.00 \pm 1.6$ & $6.67 \pm 1.0$ \\
\hline P40-P60 & 10 & 6 & $25.01 \pm 2.9$ & $7.56 \pm 1.3$ \\
\hline$>$ P70 & 10 & 5 & $30.65 \pm 3.4$ & $6.35 \pm 0.9$ \\
\hline
\end{tabular}

\begin{tabular}{|c|c|c|c|c|}
\hline PNs & $\mathrm{n}$ & $\mathrm{N}$ & sEPSC ampl. (pA) & sEPSC freq. (Hz) \\
\hline$<$ P20 & 11 & 5 & $7.37 \pm 0.4$ & $8.03 \pm 1.4$ \\
\hline P25-P32 & 12 & 6 & $9.53 \pm 0.6$ & $7.24 \pm 0.9$ \\
\hline P40-P60 & 18 & 7 & $8.28 \pm 0.6$ & $8.66 \pm 1.4$ \\
\hline$>$ P70 & 13 & 6 & $9.55 \pm 0.7$ & $5.82 \pm 1.2$ \\
\hline \multicolumn{1}{|c|}{} & sIPSC ampl. (pA) & sIPSC freq. (Hz) \\
\hline <P20 & 10 & 2 & $36.26 \pm 3.5$ & $3.013 \pm 0.6$ \\
\hline P25-P32 & 7 & 3 & $35.01 \pm 3.4$ & $5.68 \pm 1.0$ \\
\hline P40-P60 & 10 & 5 & $34.47 \pm 3.3$ & $4.60 \pm 0.6$ \\
\hline$>$ P70 & 9 & 4 & $36.50 \pm 4.5$ & $5.91 \pm 1.1$ \\
\hline
\end{tabular}

sEPSC: spontaneous excitatory postsynaptic currents. sIPSC: spontaneous inhibitory postsynaptic currents. Mean values \pm SEM. $n=$ number of cells, $N=$ number of mice. 